\title{
Haploinsufficiency in Peptidylglycine $\alpha$-Amidating Monooxygenase Leads to Altered Synaptic Transmission in the Amygdala and Impaired Emotional Responses
}

\author{
Eric D. Gaier, ${ }^{1}$ Ramona M. Rodriguiz, ${ }^{2}$ Xin-Ming M. Ma, ${ }^{1}$ Shobhana Sivaramakrishnan, ${ }^{4}$ Danielle Bousquet-Moore, ${ }^{1,2}$ \\ William C. Wetsel, ${ }^{2,3}$ Betty A. Eipper, ${ }^{1}$ and Richard E. Mains ${ }^{1}$ \\ ${ }^{1}$ Neuroscience Department, University of Connecticut Health Center, Farmington, Connecticut 06053, ${ }^{2}$ Department of Psychiatry and Behavioral Sciences, \\ Mouse Behavioral and Neuroendocrine Analysis Core Facility, and ${ }^{3}$ Departments of Psychiatry and Behavioral Sciences, Neurobiology, and Cell Biology, \\ Duke University Medical Center, Durham, North Carolina 27710, and ${ }^{4}$ Department of Anatomy and Neurobiology, Northeastern Ohio Universities College \\ of Medicine and Pharmacology, Rootstown, Ohio 44272
}

The mammalian amygdala expresses various neuropeptides whose signaling has been implicated in emotionality. Many neuropeptides require amidation for full activation by peptidylglycine $\alpha$-amidating monooxygenase (PAM), a transmembrane vesicular cuproenzyme and regulator of the secretory pathway. Mice heterozygous for the Pam gene ( $\left.\mathrm{PAM}^{+/-}\right)$exhibit physiological and behavioral abnormalities related to specific peptidergic pathways. In the present study, we evaluated emotionality and examined molecular and cellular responses that characterize neurophysiological differences in the $\mathrm{PAM}^{+/-}$amygdala. $\mathrm{PAM}^{+/-}$mice presented with anxiety-like behaviors in the zero maze that were alleviated by diazepam. PAM ${ }^{+/-}$animals were deficient in short- and long-term contextual and cued fear conditioning and required higher shock intensities to establish fear-potentiated startle than their wild-type littermates. Immunohistochemical analysis of the amygdala revealed PAM expression in pyramidal neurons and local interneurons that synthesize GABA. We performed whole-cell recordings of pyramidal neurons in the $\mathrm{PAM}^{+/-}$amygdala to elucidate neurophysiological correlates of the fear behavioral phenotypes. Consistent with these observations, thalamic afferent synapses in the PAM ${ }^{+/-}$lateral nucleus were deficient in long-term potentiation. This deficit was apparent in the absence and presence of the $\mathrm{GABA}_{\mathrm{A}}$ receptor antagonist picrotoxin and was abolished when both $\mathrm{GABA}_{\mathrm{A}}$ and $\mathrm{GABA}_{\mathrm{B}}$ receptors were blocked. Both evoked and spontaneous excitatory signals were enhanced in the $\mathrm{PAM}^{+/-}$lateral nucleus. Phasic GABAergic signaling was also augmented in the $\mathrm{PAM}^{+/-}$amygdala, and this difference comprised activity-independent and -dependent components. These physiological findings represent perturbations in the PAM ${ }^{+I-}$ amygdala that may underlie the aberrant emotional responses in the intact animal.

\section{Introduction}

Neuropeptides are the most diverse class of neurotransmitters, and many share a common biosynthetic pathway. Peptide $\alpha$-amidation is a final and often essential final step in conferring full biological activity to many neuropeptides (Eipper and Mains, 1988; Eipper et al., 1992). In mammals, this reaction is performed exclusively by a single vesicular transmembrane protein, peptidylglycine $\alpha$-amidating monooxygenase (PAM) (Eipper et al., 1983; Mains et al., 1991). PAM has two luminal enzymatic domains [peptidylglycine $\alpha$ hydroxylating monooxygenase (PHM); peptidyl $\alpha$-hydroxyglycine $\alpha$-amidating lyase (PAL)] that act sequentially to catalyze the $\mathrm{Cu}$ dependent cleavage of a C-terminal glycine (Prigge et al., 1997, 2000). The inherently unstructured cytosolic domain of PAM is multiply phosphorylated (Yun et al., 1995; Steveson et al., 1997;

\footnotetext{
Received April 29, 2010; revised July 13, 2010; accepted Aug. 9, 2010.

This work was supported by National Institutes of Health Grants DK32949 (B.A.E., R.E.M.), NS41224, and MH60451 (W.C.W.). We thank Darlene D'Amato and Yanping Wang for tireless support in the laboratory. We also thank Drs. Srdjan Antic and Eric Levine for many helpful discussions and solutions of technical challenges. Correspondence should be addressed to R. E. Mains at the above address. E-mail: mains@uchc.edu. DOI:10.1523/JNEUROSCI.2200-10.2010

Copyright $\odot 2010$ the authors $\quad 0270-6474 / 10 / 3013656-14 \$ 15.00 / 0$
}

Rajagopal et al., 2009), can regulate the peptidergic exocytic pathway (Ciccotosto et al., 1999; Alam et al., 2001), and can signal to the nucleus (Rajagopal et al., 2009).

Our group has previously described a model of genetic PAM deficiency (Czyzyk et al., 2005; Bousquet-Moore et al., 2009). Homozygous deletion of Pam results in embryonic lethality at embryonic day 14.5 and a phenotype similar to that of mice lacking the precursor of adrenomedullin, an amidated peptide (Caron and Smithies, 2001). Heterozygous mice $\left(\mathrm{PAM}^{+/-}\right)$, with half the normal levels of PAM protein and amidating activity, grow normally and reproduce but exhibit striking physiological and behavioral abnormalities (Bousquet-Moore et al., 2009, 2010) including impaired vasoconstriction and temperature regulation, a hypersensitivity to pentylenetetrazol-induced seizures, augmented anxiety-like behaviors, and disrupted $\mathrm{Cu}$ homeostasis. Here we report deficits in fear responses in $\mathrm{PAM}^{+/-}$mice, prompting our exploration of synaptic transmission in the $\mathrm{PAM}^{+/-}$amygdala.

The amygdala is a heterogeneous group of limbic nuclei that play a critical role in mediating fear and anxiety-like behaviors (Sah et al., 2003; LeDoux, 2007). The basolateral complex, composed of lateral and basolateral nuclei, receives the majority of 
inputs to the amygdala. Inhibition of these nuclei by local interneurons is crucial in maintaining low baseline amygdala activity and gating plasticity at excitatory afferent synapses (Marowsky et al., 2005; Muller et al., 2006; Shaban et al., 2006; Tully et al., 2007). Among these afferent pathways are inputs carrying discrete sensory information relevant to pavlovian fear conditioning, a behavioral model for fear learning and memory (Maren and Quirk, 2004; Pare et al., 2004; Lanuza et al., 2008).

PAM mRNA is present throughout the rodent CNS, including cortex, hippocampus, and amygdala (Schafer et al., 1992). In this study, we show that PAM protein is expressed in pyramidal neurons and interneurons of the basolateral complex. Pyramidal neurons and interneurons secrete neuropeptides in addition to glutamate and GABA (Salio et al., 2006). Altered function of these neurons, resulting from PAM limitation, could disrupt the excitatory-inhibitory balance of sensitive brain regions and affect behavior. To investigate this hypothesis, we performed electrophysiological studies in the basolateral complex of the $\mathrm{PAM}^{+/-}$ amygdala. Impairment of synaptic plasticity at thalamic afferent synapses, increased neural excitability that was $\mathrm{GABA}_{\mathrm{A}}$ dependent, and enhanced activity-dependent GABAergic transmission were evident in the $\mathrm{PAM}^{+/-}$amygdala. Collectively, these findings demonstrate that $\mathrm{PAM}^{+/-}$mice provide a unique model for peptidergic disruption with behavioral and physiological perturbations that may be relevant to anxiety-spectrum disorders in humans.

\section{Materials and Methods}

\section{Animals}

Male and female mice for these studies were generated from wild type with $\mathrm{PAM}^{+/-}$pairing in the University of Connecticut Health Center (UCHC) animal facility. Wild-type and PAM ${ }^{+/-}$littermates ( $>20$ generations bred into C57/BL6J background) were weaned between postnatal days 19 and 21 and group housed until experiments. Animals were maintained under a $12 \mathrm{~h}$ light/dark cycle (lights on at 7:00 A.M.) and were given ad libitum access to food and water. The behavioral experiments were conducted at Duke University between 11:00 A.M. and 2:00 P.M., where adult male and female wild-type and PAM ${ }^{+/-}$mice (12-20 weeks of age) were tested. Since no sex differences were observed, the data were collapsed across this variable. All experiments were conducted with approved protocols from the UCHC and Duke University Institutional Animal Care and Use Committees and in accordance with National Institutes of Health guidelines for animal care.

\section{Behavior}

Drugs. Diazepam (Sigma-Aldrich) was dissolved in sterile water containing $<0.3 \%$ Tween 80 (Sigma-Aldrich) of the total volume. The vehicle or benzodiazepine (diazepam) was administered (intraperitoneally) $30 \mathrm{~min}$ before testing.

Neurophysiological screen. The details of the tests used for assessment of general sensory and motor function and spontaneous activity in the open field have been described previously (Pogorelov et al., 2005; Taylor et al., 2008).

Zero maze. The details of the zero maze have been published previously (Pogorelov et al., 2005). The maze was illuminated at 50-60 lux and enclosed by black curtains. A video camera was positioned $100 \mathrm{~cm}$ above the maze. Naive mice were placed into a closed quadrant and permitted to investigate the maze for $5 \mathrm{~min}$. The videotapes were analyzed with Noldus Observer (Noldus Information Technology) and scored for percentage of time spent in the open areas, latency to enter the open areas, and number of head dips and freezing episodes (see below for definition).

Fear conditioning. Details of the fear-conditioning tests have been published previously (Taylor et al., 2008). Mice were assigned to one of four test groups: $1 \mathrm{~h}$ context, $24 \mathrm{~h}$ context, $1 \mathrm{~h}$ cued, and $24 \mathrm{~h}$ cued. All mice were conditioned with a single $30 \mathrm{~s}, 72 \mathrm{~dB}$ tone [conditioned stimulus (CS)] and $2 \mathrm{~s}, 0.4 \mathrm{~mA}$ scrambled footshock [unconditioned stimulus
(UCS)] on day 1. One-half of the animals were examined $1 \mathrm{~h}$ after conditioning either in the context or in the cued test, and the remainder were evaluated separately $24 \mathrm{~h}$ later in these two respective tests. Context testing consisted of returning the mouse to the same chamber in which the CS-UCS pairing had been presented. For cued tests, the mice were placed into a novel chamber with a different level of illumination, floor, walls, shape, and dimensions than the conditioning chamber. All tests were videotaped, and the behaviors were later scored using the Noldus Observer by a trained observer who was blind to the genotype of the mice and time interval of testing. Freezing was defined as the lack of all movement by the animal except for respiration for $>1 \mathrm{~s}$ (Anagnostaras et al., 2000; Porton et al., 2009).

Fear-potentiated startle. This test has been described in detail previously (Taylor et al., 2008). Testing was conducted in a MED Associates apparatus over $5 \mathrm{~d}$. On day 1, baseline startle responses were assessed over 18 trials with $40 \mathrm{~ms}$ bursts of white noise at 100,105 , and $110 \mathrm{~dB}$ presented in pseudorandom order with an intertrial interval of 30-90 s. On day 2 , one-half of the startle stimuli were administered immediately after a $30 \mathrm{~s}, 12 \mathrm{kHz}, 70 \mathrm{~dB}$ pure tone $(\mathrm{CS})$; the other half were presented without the CS. Twenty-four hours later, mice were conditioned with 10 CS-UCS pairings. One-half of the mice were conditioned with $0.25 \mathrm{~s}, 0.4$ $\mathrm{mA}$, and the remainder was conditioned with $0.6 \mathrm{~mA}$ scrambled shock (UCS). Forty-eight hours later, mice were tested for potentiation of their startle responses by the CS using the same procedure described for day 2 . Potentiation to the CS was defined as the percentage increase in the startle response for the CS plus startle-stimulus trials relative to the baseline startle responses on day 1 .

Shock-threshold testing. This procedure has been described previously (Grove et al., 2004; Taylor et al., 2008). Briefly, mice were acclimated to a single test chamber (MED Associates) for $2 \mathrm{~min}$ before being presented with five different footshock intensities $(0,0.1,0.2,0.4$, and $0.6 \mathrm{~mA})$ for $2 \mathrm{~s}$. Intershock intervals were between 30 and $90 \mathrm{~s}$. Behavioral responses were videotaped and scored subsequently using the Noldus Observer program. Behaviors were given scores of $0-5$. A score of 0 denoted the lowest level of response that involved the continuation of activity. A score of 1 signified a low-level response to shock that included freezing, face wiping, self-grooming, shaking, or rapid forward departures. A score of 2 was a moderate response that could involve retreating from shock or tail rattling. A score of 3 denoted stationary reactive responses including kicking and vocalization. A score of 4 signified locomotor reactivity such as darting and leaping. A score of 5 was indicative of jumping against the walls or ceiling of the chamber. Behavioral scores were summed for each animal and analyzed as a function of genotype and shock intensity.

\section{Immunocytochemistry}

Immunohistochemical staining of tissue sections from perfusion-fixed mice has been described previously (Ma et al., 2001, 2002, 2008). Briefly, male wild-type and $\mathrm{PAM}^{+/-}$littermates were perfused transcardially with $4 \%$ formaldehyde $/ 0.1$ m sodium phosphate buffer, $\mathrm{pH} 7.4$, under deep ketamine anesthesia. After fixation, brains were postfixed in $4 \%$ paraformaldehyde for $3 \mathrm{~h}$. Coronal sections were cut $(15 \mu \mathrm{m})$ through the amygdala using a cryostat and immunostained with rabbit antiserum JH629 to the exon A (exon 16) region of PAM1 (Maltese and Eipper, 1992), mouse monoclonal IgG to GAD67 (Millipore), Alexa-488 donkey anti-rabbit [heavy and light chains $(\mathrm{H}+\mathrm{L})$ ] (Invitrogen), and Cy3-conjugated AffiniPure $\mathrm{F}\left(\mathrm{ab}^{\prime}\right)_{2}$-fragment donkey anti-mouse $(\mathrm{H}+\mathrm{L})$ (Jackson ImmunoResearch Laboratories) as described previously (Ma et al., 2001).

\section{Electrophysiology}

Slice preparation. Male wild-type and $\mathrm{PAM}^{+/-}$littermates 4-7 weeks of age were decapitated, and their brains were quickly removed into icecold artificial CSF (aCSF) containing (in mM) $125 \mathrm{NaCl}, 26 \mathrm{NaHCO}_{3}, 10$ glucose, $2.3 \mathrm{KCl}, 2 \mathrm{CaCl}_{2}, 2 \mathrm{MgSO}_{4}$, and $1.26 \mathrm{KH}_{2} \mathrm{PO}_{4}$ (aerated with $95 \%$ $\mathrm{O}_{2}$ and $5 \% \mathrm{CO}_{2}$, pH 7.3, $310 \mathrm{mOsm} / \mathrm{kg}$ ) (Zhou et al., 2008). Coronal slices, $300 \mu \mathrm{m}$ thick, were incubated at room temperature for at least $1 \mathrm{~h}$ before recordings.

Whole-cell recordings. Slices were transferred to a recording chamber heated to $32^{\circ} \mathrm{C}$ and perfused with aerated aCSF. Recording pipettes had 3-5 $\mathrm{M} \Omega$ tips. The internal pipette solution used in most experiments was 
composed of (in mM) $135 \mathrm{~K}$-gluconate, 10 HEPES, 10 P-creatine, 3 $\mathrm{Na}_{2} \mathrm{ATP}, 2 \mathrm{MgCl}_{2}$, and $0.3 \mathrm{Na}_{2} \mathrm{GTP}(\mathrm{pH} 7.3,285 \mathrm{mOsm} / \mathrm{kg}$ ) (Zhou et al., 2008). IPSCs were recorded using a pipette solution composed of (in mM) $120 \mathrm{CsCl}, 10 \mathrm{HEPES}, 1$ EGTA, $0.1 \mathrm{CaCl}_{2}, 1.5 \mathrm{MgCl}_{2}, 4 \mathrm{Na}_{2}$-ATP, 0.3 $\mathrm{Na}_{2}$-GTP, and 5 QX-314 (pH 7.3, $310 \mathrm{mOsm} / \mathrm{kg}$ ). Neurons were patched under visual guidance using infrared differential interference contrast optics. Data were collected using a Multiclamp 700B amplifier (Molecular Devices) and analyzed using pClamp 9.2 software (Molecular Devices).

Evoked synaptic transmission. Synaptic activity was evoked using 200 $\mu$ s current pulses elicited with a Master 8 and an ISO-Flex stimulator (A.M.P.I.) through bipolar tungsten electrodes (World Precision Instruments). Electrode placement in the internal and external capsules preferentially stimulated afferent axons originating in thalamic and cortical areas, respectively (Weisskopf and Ledoux, 1999). Input-output curves for thalamic and cortical inputs were generated from excitatory and inhibitory compound currents recorded at $V_{\text {holding }}=-55 \mathrm{mV}$. Only outward currents were sensitive to picrotoxin (PTX; data not shown). AMPA and NMDA receptor-mediated currents were recorded at $V_{\text {holding }}=-70$ and $+50 \mathrm{mV}$, respectively. NMDA receptor-mediated current amplitude was measured $50 \mathrm{~ms}$ after the stimulus to avoid contamination by the AMPA component. For the majority of neurons recorded in these experiments, reversal potentials were assessed by recording currents at voltages between -70 and $+50 \mathrm{mV}$ in $10 \mathrm{mV}$ increments. Reversal potential was calculated as the $\mathrm{X}$-intercept of a fit to the linear portion of the $I-V$ curve for each neuron. A two-term exponential curve was fit to each $+50 \mathrm{mV}$ current trace to assess fast and slow decay components of the mixed AMPA- and NMDA-mediated current. To record evoked IPSCs (eIPSCs), placement of the stimulating electrode locally in the amygdala neuropil medial to the recording pipette allowed preferential stimulation of local interneurons (Marowsky et al., 2005; Silberman et al., 2008) and was kept as consistent as possible. The axonal arbors of amygdalar interneurons are extensive, often encompassing the whole basolateral nucleus (Rainnie et al., 2006). In addition, parvalbumin-positive amygdalar interneurons (the most prevalent class of interneuron) are electrically coupled via dendritic and axonal gap junctions (Muller et al., 2005). Therefore, action potential activity could be produced reliably through local stimulation pulses and maximal responses consistently achieved in a given amygdala slice. Paired pulses were applied, and the ratio of the second eIPSC amplitude to the first was interpreted as an inverse indicator of release probability.

Synaptic plasticity. Stimulating electrodes were placed in the internal capsule to evoke thalamic afferents (Weisskopf et al., 1999; Tully et al., 2007). In whole-cell configuration, experiments were conducted in current-clamp mode in the presence and absence of PTX. The holding current was adjusted to maintain $V_{\mathrm{m}}=-70 \mathrm{mV}$ throughout the course of experiments. The $10-90 \%$ rise slope of EPSPs was used as the measure of synaptic efficacy. Stimulation strength was adjusted to produce a 3-6 $\mathrm{mV}$ EPSP, and test stimuli were applied at $0.1 \mathrm{~Hz}$. After establishment of a steady baseline, long-term potentiation (LTP) was induced using an action potential pairing induction protocol. This induction paradigm was originally characterized as being L-type voltage-gated calcium channel dependent (Bauer et al., 2002). Fifteen paired trains were applied at $0.1 \mathrm{~Hz}$; each train consisted of 10 pulses at $30 \mathrm{~Hz}$ paired with $2.5 \mathrm{~ms}$ current pulses of $+1 \mathrm{nA}$ or greater to elicit an action potential at a $5 \mathrm{~ms}$ delay to the onset of each synaptic event. If $1 \mathrm{nA}$ was not sufficient, then the pulse amplitude was increased by $+50 \mathrm{pA}$ until action potentials were observed throughout the train. LTP was measured as the normalized fractional difference between the 35-40 min interval after induction and the $5 \mathrm{~min}$ interval before induction; neurons were pooled by genotype. Only one neuron was used per slice. For field-potential (FP) recordings, pulse durations were $100 \mu$ s. Recording pipettes (3-5 M $\Omega$ ) were filled with aCSF and placed in the neuropil of the lateral amygdala. Fast GABAergic transmission was blocked using $100 \mu \mathrm{M}$ PTX throughout these experiments. Stimulation strength was adjusted to achieve $30-50 \%$ of the maximum voltage response for each slice. The same stimulation strength was used for test stimulation and induction. At least $20 \mathrm{~min}$ of stable baseline was recorded before applying the induction protocol. Theta burst stimulation consisted of four sets at 20 s intervals; each set included 10 bursts at $200 \mathrm{~ms}$ intervals; each burst was four pulses at $100 \mathrm{~Hz}$. Test stimulation responses for the $10 \mathrm{~min}$ before induction and between 50 and $60 \mathrm{~min}$ after induction were used in the assessment of plasticity.

Membrane properties. A series of negative and positive current steps were applied immediately after achieving whole-cell configuration $(25 \times$ $50 \mathrm{pA}$ steps, -300 to $+900 \mathrm{pA} ; 500 \mathrm{~ms}$ steps). The six initial negative steps were used to calculate membrane resistance; single exponential curve fits yielded time constant $(\tau)$ and capacitance values. Action potential threshold was defined and measured as the point of voltage inflection for the first spike fired in the lowest current step. An action potential was defined as a brief, accelerating depolarization $>20 \mathrm{mV}$ in amplitude.

Nonevoked synaptic transmission. All nonevoked synaptic activity was recorded at $V_{\text {holding }}=-70 \mathrm{mV}$. Synaptic events were filtered at $1 \mathrm{kHz}$ and analyzed using MiniAnalysis (Synaptosoft). Events were pooled by experimental condition for statistical comparison. To avoid overrepresentation of neurons with higher frequencies in our analyses, the smallest number of events recorded from a single neuron in an experiment was used as the number of consecutive event values each neuron contributed to the pool. Spontaneous EPSCs (sEPSCs) were quantified using the fifth minute of activity after whole-cell conversion for each neuron. For spontaneous IPSCs (sIPSCs) and miniature IPSCs (mIPSCs), the eighth minute of activity was analyzed for each neuron to allow equilibration of the pipette solution. Threshold amplitudes were set at $7 \mathrm{pA}$ for sEPSCs and 20 pA for sIPSCs and mIPSCs; these values were based on the root mean square of the baseline noise from wild-type recordings at multiples of four and five, respectively (Zhang et al., 2009).

Pharmacology. All drugs were applied through the perfusate. PTX (100 $\mu \mathrm{M}$; Sigma-Aldrich) was used to block fast $\mathrm{GABA}_{\mathrm{A}}$ receptor-mediated transmission. CGP35348 (1 $\mu \mathrm{M}$; Tocris Biosciences) was used to block slow $\mathrm{GABA}_{\mathrm{B}}$ receptor-mediated transmission. Tetrodotoxin (TTX; $1 \mu \mathrm{M}$; Alomone Labs) was used to block action potential-dependent activity. 6,7-dinitroquinoxaline-2,3-dione (DNQX; $10 \mu \mathrm{m}$; Sigma-Aldrich) or 6-cyano-7-nitroquinoxaline-2,3-dione (CNQX; $10 \mu \mathrm{M}$; Tocris Biosciences) and 3-(2-carboxypiperazin-4-yl)propyl-1-phosphonic acid (3 $\mu \mathrm{M}$; Tocris Biosciences) were used to block glutamatergic transmission while recording inhibitory synaptic transmission. CNQX and DNQX stocks were prepared in DMSO; the final concentration of DMSO in the recording solution was $0.01 \%$. All other drug stocks were prepared in water.

\section{Statistics}

For behavioral data, zero maze responses were analyzed by two-way ANOVA where genotype and treatment were examined; average percentage freezing responses in contextual fear conditioning were evaluated for genotype and test time. Repeated-measures ANOVA (RMANOVA) was used to examine fear-conditioning responses over time where withinsubject effects were applied to the 1 min observations and betweensubject effects for genotype and test time (i.e., 1 or $24 \mathrm{~h}$ ). RMANOVA was also used to evaluate freezing responses in cued fear conditioning during the pre-CS and CS intervals and for fear-potentiated startle where the within-subject effects were applied to the three startle stimulus intensities and the between-subjects effect was applied to the two shock intensities and genotypes. The interactions were decomposed by Bonferronicorrected pairwise comparisons. In all cases, a $p \leq 0.05$ was considered significant.

For synaptic plasticity experiments, LTP was calculated using averaged values of EPSP rise slope -5 to 0 before and 35-40 min after AP pairing or FP rise slope -10 to 0 before and 50-60 min after theta burst stimulation. Successful LTP was defined within a group by Wilcoxon signed rank test comparisons to baseline and within a neuron as $\geq 1.15$ of baseline. Comparisons of proportions of neurons that potentiated between groups used $z$ tests. Comparisons between mean LTP values between groups used unpaired $t$ tests. ANOVA (one- and two-way) were used as indicated for analyses involving genotype (wild type vs $\mathrm{PAM}^{+/-}$) and/or treatment (aCSF vs PTX or mIPSC vs SIPSC). These include membrane properties, sEPSC, and mIPSC/sIPSC. RMANOVA was used to make genotypic comparisons across within-subject treatments (e.g., serial current steps or stimulation intensities). Unpaired $t$ tests were used to detect 

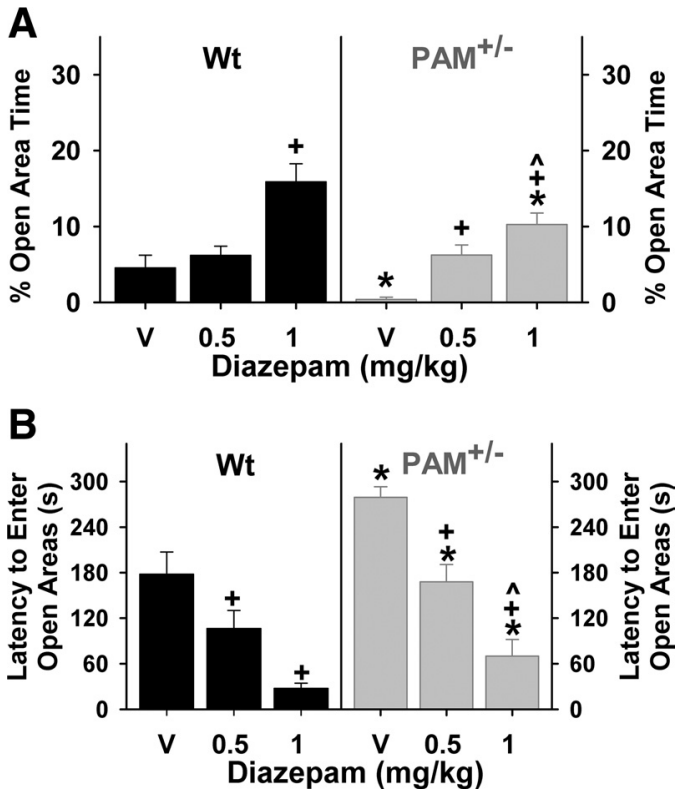

Figure 1. $\mathrm{PAM}^{+/-}$mice display anxiety-like behaviors that are alleviated with diazepam. Wild-type $\left(\mathrm{Wt}\right.$ ) and PAM ${ }^{+/-}$littermates received vehicle, 0.5 or $1 \mathrm{mg} / \mathrm{kg}$ diazepam (intraperitoneally) and were tested in the zero maze 30 min later. $A$, Effects of diazepam on percentage of time spent in the open areas by Wt and PAM ${ }^{+/-}$mice. $\boldsymbol{B}$, Diazepam effects on the latency to first enter the open areas. ${ }^{*} p \leq 0.05$, compared with Wt mice; ${ }^{+} p<0.05$, compared with vehicle treatment within genotype; $\wedge p<0.05$, compared with vehicle-treated Wt mice between genotypes (ANOVA, Bonferroni-corrected pairwise comparisons). $n=10-13$ mice per genotype per treatment.

differences for individual treatments. In all cases, a $p \leq 0.05$ was considered significant.

\section{Results}

$\mathrm{PAM}^{+/-}$mice present with an anxiety-like phenotype that is alleviated with diazepam

A general assessment of sensory and motor function revealed the wild-type and $\mathrm{PAM}^{+/-}$animals to be indistinguishable (supplemental Table S1, available at www.jneurosci.org as supplemental material). Naive PAM ${ }^{+/-}$mice display anxiety-like behaviors in the elevated zero maze (Bousquet-Moore et al., 2010), where reduced time in the open areas is the major indicator of this response (Shepherd et al., 1994). To determine whether this behavior was responsive to anxiolytic drugs, wild-type and $\mathrm{PAM}^{+/-}$animals were given vehicle or diazepam. As reported, vehicle-treated $\mathrm{PAM}^{+/-}$mice spent less time in the open areas than wild-type controls $(p=0.05)$ (Fig. 1A). Diazepam dosedependently increased open area time in both genotypes; however, anxiolytic responses to diazepam were different between genotypes. For wild-type animals, $1 \mathrm{mg} / \mathrm{kg}$ diazepam was required to significantly increase open area time $(p<0.001)$, whereas both doses were sufficient for PAM ${ }^{+/-}$animals $(p<$ 0.01 ). The response in mutants to $0.5 \mathrm{mg} / \mathrm{kg}$ diazepam was similar to that of the vehicle wild-type controls; the $1 \mathrm{mg} / \mathrm{kg}$ dose increased the open area time of wild-type mice more than $\mathrm{PAM}^{+/-}$mice $(p<0.05)$. The latency to first enter an open area revealed wild-type mice to have shorter latencies than $\mathrm{PAM}^{+/-}$ animals $(p<0.01)$ (Fig. $1 B)$. Diazepam reduced these latencies relative to vehicle for the genotypes at both doses $(p<0.05)$. Both doses of diazepam were less efficacious in $\mathrm{PAM}^{+/-}$mice than in wild-type controls $(p \leq 0.05)$. Diazepam also dosedependently increased head dipping and decreased freezing behaviors in both genotypes (supplemental Fig. S1 $A, B$, available at
A

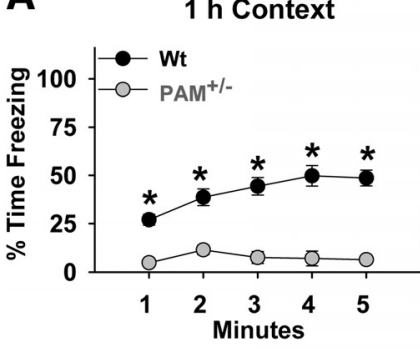

B

C

$1 \mathrm{~h}$ Cued
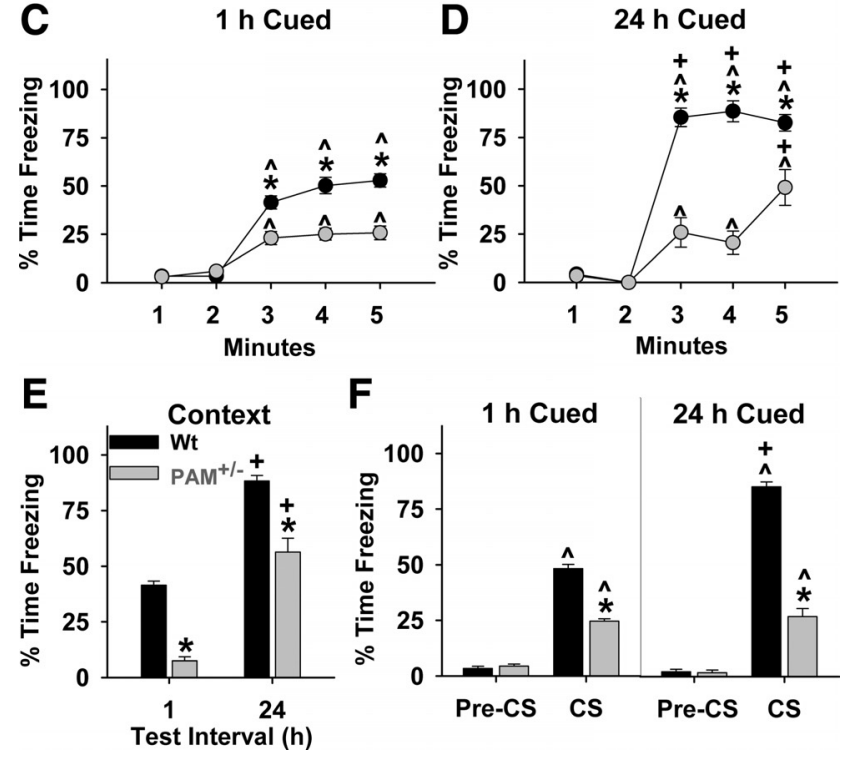

F $\quad 1$ h Cued

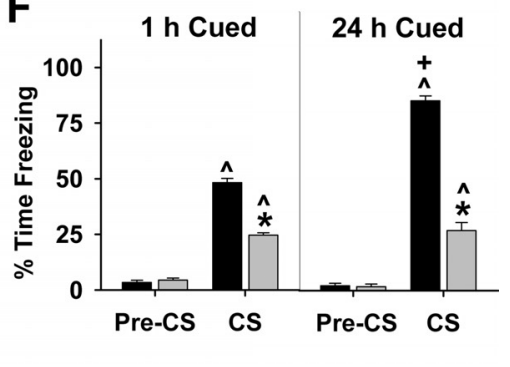

Figure 2. $\mathrm{PAM}^{+/-}$mice are deficient in fear conditioning. Wild-type $(\mathrm{Wt})$ and $\mathrm{PAM}^{+/-}$ littermates were conditioned and tested 1 or $24 \mathrm{~h}$ later in context- and cue-dependent fear conditioning. $\boldsymbol{A}, \boldsymbol{B}$, Percentage of time freezing during context testing $1 \mathrm{~h}(\boldsymbol{A})$ or $24 \mathrm{~h}(\boldsymbol{B})$ after conditioning. Animals were tested in the same chamber in which they had been conditioned, but in the absence of the $C S$ and UCS. C, D, Percentage of time freezing during cued testing $1 \mathrm{~h}$ $(\boldsymbol{C})$ or $24 \mathrm{~h}(\boldsymbol{D})$ after conditioning. In cued testing, animals were tested in a novel chamber, and after $2 \mathrm{~min}$, the $C S$ was presented in the absence of the UCS. $E$, Mean percentage of time freezing by $\mathrm{Wt}$ and $\mathrm{PAM}^{+/-}$mice over the 5 min context test, conducted 1 and $24 \mathrm{~h}$ after conditioning. $F$, Mean percentage of time freezing by $\mathrm{PAM}^{+/-}$mice during cued testing at $1 \mathrm{~h}$ (left) and $24 \mathrm{~h}$ (right) after conditioning; the pre-CS results are averaged over the first $2 \mathrm{~min}$ interval, and the $C S$ results are over the final 3 min of testing during $C S$ presentation. ${ }^{*} p<0.05$, compared with Wt mice; ${ }^{+} p<0.05$, compared with freezing responses at $1 \mathrm{~h} ; \wedge p<0.05$, compared with the pre-CS interval in the cued test (ANOVA, RMANOVA, Bonferroni-corrected pairwise comparisons). $n=10$ mice pre genotype per test condition and time.

www.jneurosci.org as supplemental material). It also enhanced the numbers of closed-to-open-to-closed area transitions (wild type: $2.00 \pm 0.93,3.00 \pm 1.29,2.30 \pm 0.45 ; \mathrm{PAM}^{+/-}: 0.00 \pm 0.05$, $1.00 \pm 0.32,2.10 \pm 0.74$; transitions to $0,0.5$, and $1 \mathrm{mg} / \mathrm{kg} \mathrm{diaz}-$ epam, respectively). Together, these data demonstrate that $\mathrm{PAM}^{+/-}$mice present with an anxiety-like phenotype that can be alleviated with the anxiolytic drug diazepam.

$\mathrm{PAM}^{+/-}$mice are deficient in short- and long-term conditioned fear responses

Naive PAM ${ }^{+/-}$mice were examined in fear conditioning as described previously (Taylor et al., 2008; Porton et al., 2009), where a $2 \mathrm{~s}, 0.4 \mathrm{~mA}$ scrambled footshock (UCS) was paired once with a $12 \mathrm{kHz}$ tone (CS). Contextual and cued testing occurred 1 or $24 \mathrm{~h}$ after conditioning. During conditioning, no genotypic differences in freezing behavior were observed before or during presentation of the CS or after the CS-UCS pairing (supplemental Table S2, available at www.jneurosci.org as supplemental mate- 
rial). At both the 1 and $24 \mathrm{~h}$ contextual tests, freezing in $\mathrm{PAM}^{+/-}$mice was decreased relative to that for wild-type littermates $(p<0.01)$ (Fig. $2 A, B)$. This effect was also evident when freezing was collapsed over the $5 \mathrm{~min}$ interval $(p<0.001)$ (Fig. $2 E$ ). Although freezing in the context tests for both genotypes increased during the $24 \mathrm{~h}$ relative to the $1 \mathrm{~h}$ test $(p<0.001)$, freezing was reduced at both times in $\mathrm{PAM}^{+/-}$mice relative to the wild-type controls $(p<0.001)$. Hence, the $\mathrm{PAM}^{+/-}$animals are deficient in contextual fear conditioning at both 1 and $24 \mathrm{~h}$.

Similar results were observed for cued testing (Fig. 2C,D). Freezing before presentation of the CS was not different between genotypes at $1 \mathrm{~h}$ (Fig. 2C, left) or $24 \mathrm{~h}$ (Fig. 2D, left). During the 3 min CS, freezing in wild-type mice was higher than that for PAM ${ }^{+/-}$animals during both the 1 and 24 h tests $(p<0.001)$. Freezing in wild-type mice was stable across the $3 \mathrm{~min}$ period of CS presentation and was higher at $24 \mathrm{~h}$ than at $1 \mathrm{~h}(p<0.001)$. In comparison, freezing in PAM $^{+/-}$animals was only enhanced during the $24 \mathrm{~h}$ test over the last minutes compared with that during the $1 \mathrm{~h}$ test $(p<0.01)$. Analysis of collapsed data as mean percentage of freezing (Fig. $2 F$ ) demonstrated that both genotypes engaged in more freezing during the CS than the pre-CS interval $(p<$ 0.001 ). Additionally, freezing by wildtype mice during the CS presentation was higher at $24 \mathrm{~h}$ than at $1 \mathrm{~h}(p<0.001)$; this increase was not observed in the mutants. Collectively, these data demonstrate that $\mathrm{PAM}^{+/-}$mice are markedly impaired in short- and long-term contextual and cued fear conditioning. Because amygdala lesions depress freezing responses in both the contextual and cued tests whereas lesions of the hippocampus only decrease freezing in context but leave cued freezing intact (Kim and Fanselow, 1992; Phillips and Ledoux, 1992), our results suggest that $\mathrm{PAM}^{+/-}$mice may have some amygdala dysfunction.

\section{$\mathrm{PAM}^{+/-}$mice display aberrant}

\section{fear-potentiated startle responses}

Fear-potentiated startle was used to examine amygdala function in $\mathrm{PAM}^{+/-}$ mice (Taylor et al., 2008; Porton et al., 2009). Mice were conditioned at one of two shock intensities (0.4 and $0.6 \mathrm{~mA}$ ) and tested for potentiation at three different startle intensities (100, 105, and 110 dB) $48 \mathrm{~h}$ after the CS-UCS pairing. Startle responses on test days 1 and 2 did not differ among genotypes to the different UCS conditions (supplemental Fig. S2 A, B, available at www.jneurosci.org as supplemental material). Hence, baseline startle reactiv-

A

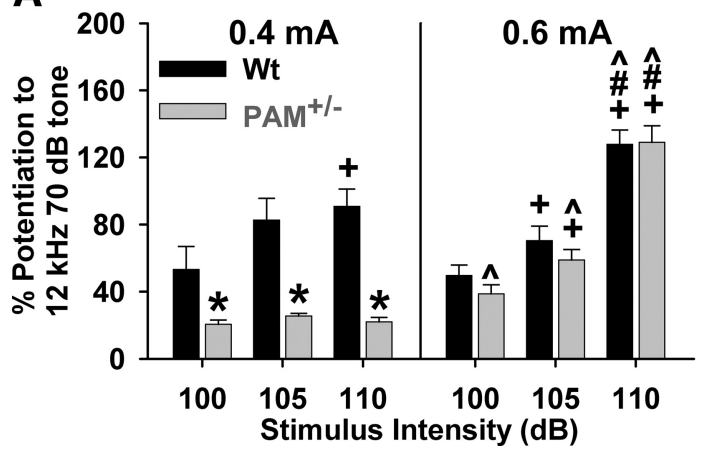

B

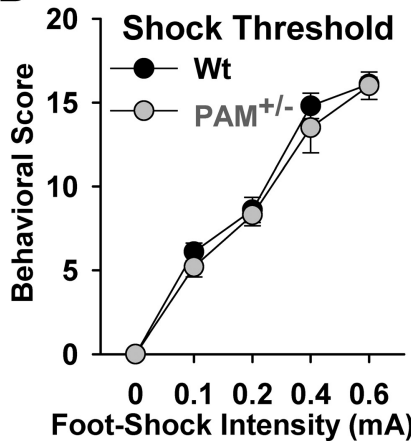

Figure 3. $\mathrm{PAM}^{+/-}$mice show abnormal fear-potentiated startle. Wild-type $(\mathrm{Wt})$ and $\mathrm{PAM}^{+/-}$littermates were conditioned with two different intensities of shock $(0.4$ and $0.6 \mathrm{~mA})$. $A$, Percentage of potentiation by $\mathrm{Wt}$ and PAM ${ }^{+/-}$mice to a $12 \mathrm{kHz}, 70 \mathrm{~dB}$ tone preceded by a 100, 105, or $110 \mathrm{~dB}$ white-noise startle stimulus; animals were conditioned with $0.4 \mathrm{~mA}$ (left) or $0.6 \mathrm{~mA}$ (right) shock. $B$, Sensitivity of Wt and PAM ${ }^{+/-}$mice to varying intensities of scrambled footshock; behavioral responses are represented by composite scores during the application of the shock. ${ }^{*} p<0.05$, compared with Wt mice; ${ }^{+} p<0.05$, compared with responses to the $100 \mathrm{~dB}$ startle stimulus; ${ }^{\#} p<0.05$, compared with responses to the $105 \mathrm{~dB}$ startle stimulus; $\wedge p<0.05$, compared with responses after $0.4 \mathrm{~mA}$ shock (ANOVA, RMANOVA, Bonferroni-corrected pairwise comparisons). $n=9-10$ mice per genotype per shock intensity for fear-potentiated startle; $n=10$ mice per genotype for shock-threshold testing.

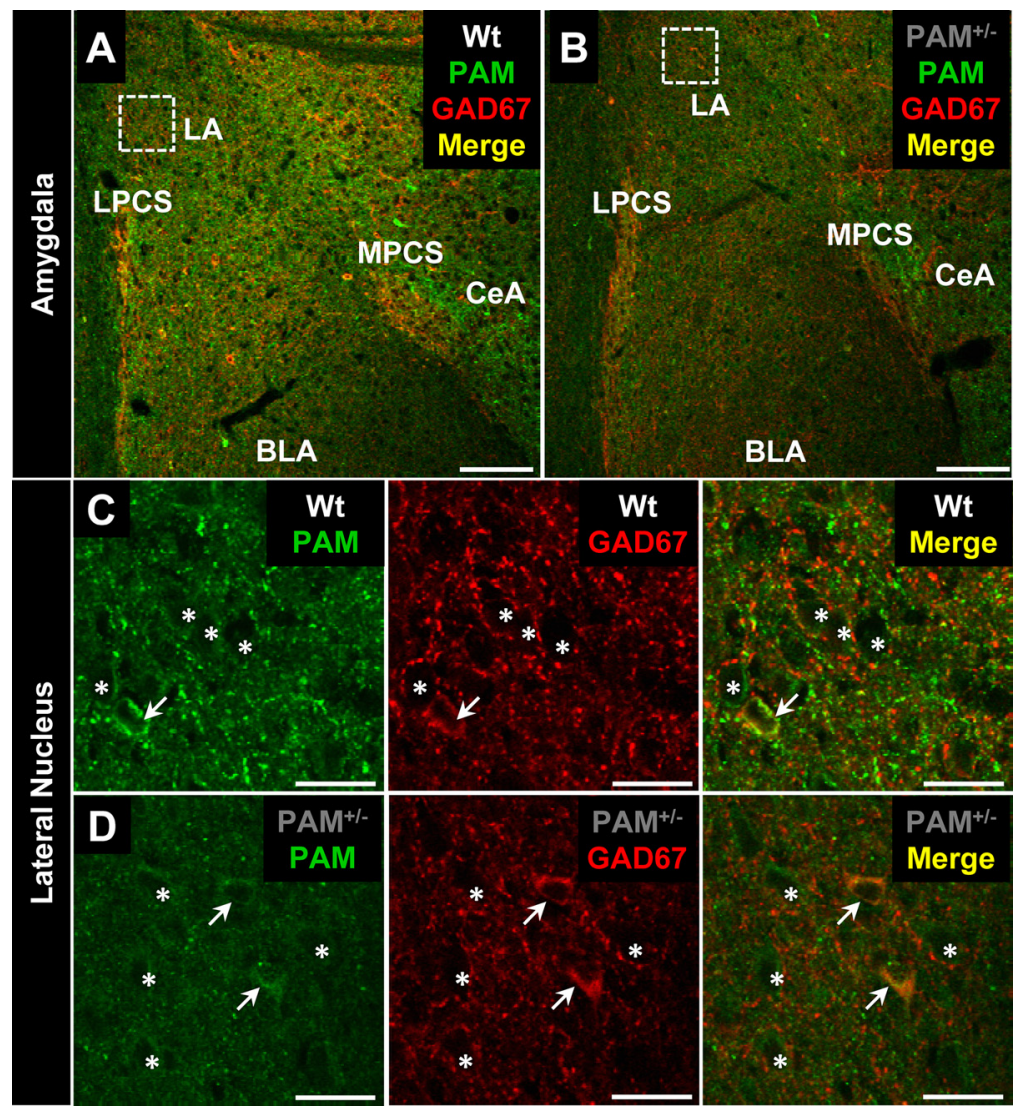

Figure 4. PAM is expressed in pyramidal neurons and interneurons in the basolateral complex. Coronal sections $(15 \mu \mathrm{m})$ through the amygdala of wild-type $(\mathrm{Wt})$ and $\mathrm{PAM}^{+1-}$ mice were immunostained simultaneously with antisera to PAM (green) and GAD67 (red). A, B, Low-power merged images of Wt and PAM ${ }^{+/-}$amygdalae. LA, Lateral amygdala; BLA, basolateral amygdala; CeA, central amygdala; LPCS, lateral paracapsular cells; MPCS, medial paracapsular cells. Scale bars, $100 \mu \mathrm{m}$. C, D, High-power images of the area in LA of Wt and PAM ${ }^{+/-}$amygdalae outlined in $\boldsymbol{A}$ and $\boldsymbol{B}$. Arrows indicate GAD67-positive interneurons. Asterisks indicate pyramidal neurons surrounded by GAD67-immunoreactive puncta representing axo-somatic GABAergic terminals. Staining for PAM was apparent in the soma of both interneurons and pyramidal neurons. Scale bars, $20 \mu \mathrm{m}$. ities and potentiation of responses to a pure tone were similar between wild-type and $\mathrm{PAM}^{+/-}$mice. Forty-eight hours after the CS-UCS pairing, animals were examined for fear-potentiated startle. When conditioned with $0.4 \mathrm{~mA}$ shock (Fig. 3A, left), 
$\mathrm{PAM}^{+/-}$mice showed significantly less potentiation of their startle responses than wild-type controls $(p<0.01)$; however, when the shock intensity was increased to $0.6 \mathrm{~mA}$, potentiation to the startle stimuli was similar between genotypes (Fig. $3 A$, right). Overall, these findings are particularly noteworthy since in shockthreshold testing (Fig. 3B), no genotype differences were discerned across different intensities of footshock, including those used in the fear-conditioning or fear-potentiated startle tests. Hence, the deficiencies of the $\mathrm{PAM}^{+/-}$mice in fear conditioning and fearpotentiated startle cannot be attributed to genotype differences in response to shock. Together with the fear-conditioning results, these findings for fear-potentiated startle strongly suggest that the amygdala is dysfunctional in PAM $^{+/-}$mice.

\section{Pyramidal neurons and interneurons of the basolateral complex express PAM}

To determine how a change in PAM expression causes these behavioral outcomes, we compared the cellular expression patterns of PAM in the basolateral complex of wild-type and PAM $^{+/-}$ amygdala. There were no gross differences in the structures of $\mathrm{PAM}^{+/-}$and wild-type amygdalae. In agreement with haploinsufficiency of the Pam gene (Czyzyk et al., 2005), PAM immunoreactivity was consistently less intense in $\mathrm{PAM}^{+/-}$compared with wild-type amygdala (Fig. 4A,B). GAD67 immunoreactivity was localized to GABAergic presynaptic terminals and the somata of amygdala interneurons (Muller et al., 2003, 2006; Rainnie et al., 2006). In the basolateral nucleus, GAD67 immunoreactivity in both genotypes was consistently stronger than in the lateral nucleus (supplemental Fig. S3A, available at www.jneurosci.org as supplemental material).

When examined at higher magnification, PAM immunoreactivity was apparent in the soma of both wild-type and $\mathrm{PAM}^{+/-}$ lateral amygdala neurons (Fig. $4 C, D$, green). Although present in secretory granules, PAM is concentrated in the trans-Golgi network and endocytic vesicles and is accumulated in the perinuclear region of the cell soma (Niciu et al., 2006). While PAM was present in both GAD67-negative pyramidal neurons (Fig. 4C,D, asterisks) and GAD67-positive interneurons (arrows), PAM immunoreactivity was more intense in interneurons. This finding is consistent with previous in situ hybridization analyses of PAM expression in the rat cerebral cortex and hippocampus (Schafer et al., 1992). Interneurons of the basolateral nucleus also exhibited stronger PAM immunoreactivities than pyramidal neurons in both genotypes (supplemental Fig. S3A, arrows, available at www.jneurosci.org as supplemental material).

In both lateral and basolateral nuclei, intense GAD67immunoreactive puncta, representing axo-somatic GABAergic synapses, surrounded the somata of pyramidal neurons (Fig. $4 C, D$; supplemental Fig. S3A, red, available at www.jneurosci.org as supplemental material). These synapses are likely contributed by local interneurons and paracapsular neurons, which mediate the tight feedforward and feedback inhibition described in these areas (Szinyei et al., 2000; Sah et al., 2003; Marowsky et al., 2005). We combined electrophysiological and pharmacological approaches to study the function of these synapses in regulating excitability and plasticity in the wild-type and $\mathrm{PAM}^{+/-}$amygdala.

\section{Deficient synaptic plasticity at $\mathrm{PAM}^{+/-}$thalamic amygdala afferents}

To investigate the neurophysiological basis for the behavioral abnormalities displayed by $\mathrm{PAM}^{+/-}$mice (Figs. 1-3), we performed several electrophysiological experiments in the $\mathrm{PAM}^{+/-}$ amygdala. Extensive experiments have demonstrated that the lat-
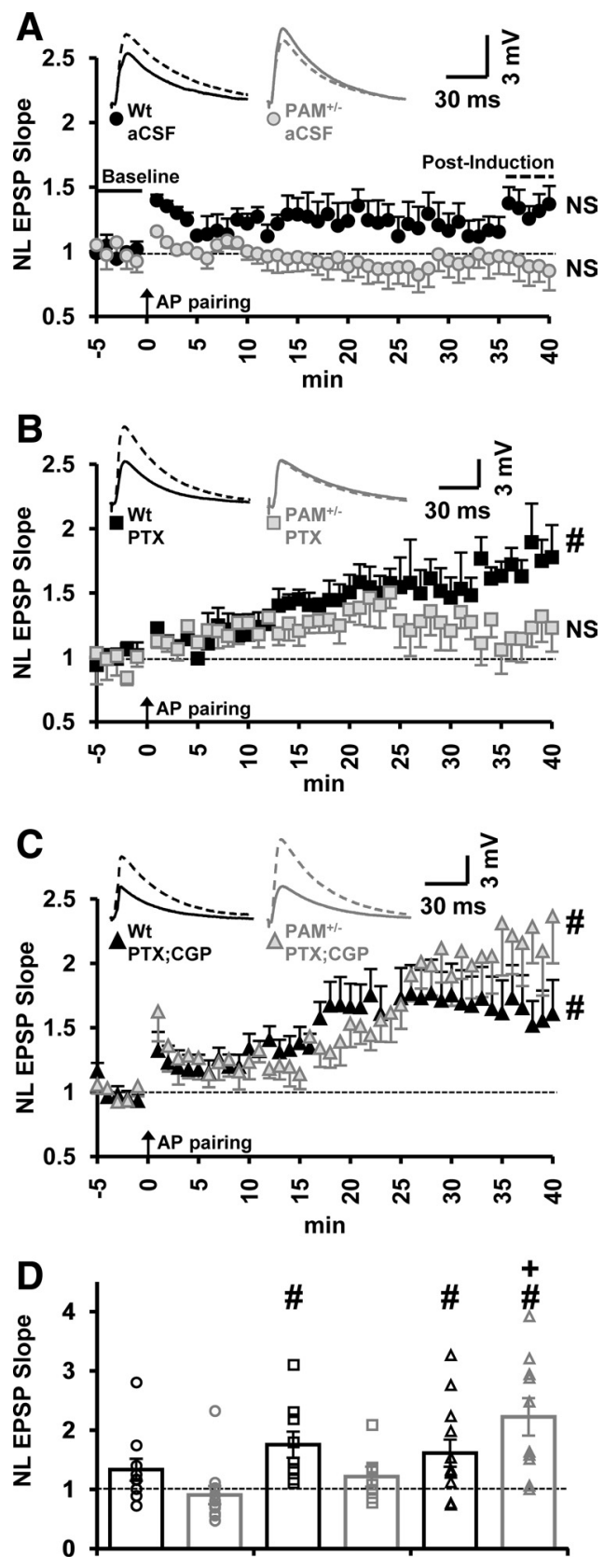

Figure 5. PAM ${ }^{+/-}$mice exhibit a deficiency in thalamic afferent LTP that relies on GABAergic transmission. Thalamic afferents were stimulated, and pyramidal neuron membrane responses were recorded in whole-cell mode in the lateral nuclei of wild-type (Wt) and PAM ${ }^{+/-}$ amygdala slices. Insets above each plot depict representative averaged traces for each genotype before (solid) and after (dashed) LTP induction as indicated (baseline and after induction). $\boldsymbol{A}-\boldsymbol{C}$, Time course (1 min bins) of averaged LTP experiments using an action potential (AP) pairing induction paradigm. Synaptic efficacy was assessed using the rise slope of EPSPs that were normalized (NL) for genotypic comparisons. Experiments were conducted in aCSF control solution $\left(\boldsymbol{A} ; n=10 \mathrm{Wt}, 11 \mathrm{PAM}^{+/-}\right)$, aCSF with $100 \mu \mathrm{M} \mathrm{PTX}\left(\boldsymbol{B} ; n=9 \mathrm{Wt}, 7 \mathrm{PAM}^{+/-}\right)$, or aCSF with PTX and (GP35348 $(1 \mu \mathrm{M})\left(\boldsymbol{C} ; n=12 \mathrm{Wt}, 10 \mathrm{PAM}^{+/-}\right)$. D , Values of LTP assessed at 40 min after induction for individual pyramidal neurons are plotted by experimental condition (data from $A-C$ ). Bars depict mean values, and error bars depict the SEM. ${ }^{\#} p<0.05$, compared with baseline; ${ }^{+} p<0.05$, compared with aCSF within genotype; NS, not significant compared to baseline; (Wilcoxon signed rank test).

eral, basolateral, and central nuclei of the amygdalae are critical to fear conditioning (Davis, 1990; Ledoux, 2000; Kim and Jung, 2006). Auditory and somatosensory inputs, which carry relevant information about the CS and UCS, terminate primarily in the 
lateral nucleus, which is essential to normal cued conditioning (Ledoux et al., 1990). Thalamic inputs to the lateral nucleus are also important at the time of the CS-UCS pairing and play a more critical role in amygdala plasticity and learning than cortical pathways and their corresponding inputs (Quirk et al., 1997).

Since PAM $^{+/-}$mice were most deficient in cued fear conditioning (Fig. 2), we assessed the status of glutamatergic synaptic plasticity at thalamic afferent synapses (Fig. 5). LTP at this synapse is the strongest neural correlate to fear learning and memory to date (Maren and Quirk, 2004; Pare et al., 2004; Sigurdsson et al., 2007; Sah et al., 2008). We stimulated thalamic afferents and recorded EPSPs in wild-type and $\mathrm{PAM}^{+/-}$pyramidal neurons from the lateral nucleus. LTP was induced by synchronized trains of afferent stimulation with postsynaptically induced action potentials. In control solution, both wildtype and $\mathrm{PAM}^{+/-}$neurons failed to potentiate consistently above baseline, and there was no difference in mean LTP values between genotypes (Fig. 5A). However, a larger proportion of wild-type neurons could be stimulated to induce LTP than PAM ${ }^{+/-}$neurons (wild type, 7 of $10 ; \mathrm{PAM}^{+/-}, 1$ of $11 ; p<0.05, z$ test $)$. Since previous LTP studies have shown that limiting fast GABAergic transmission is necessary for LTP induction in acute slices (Bauer et al., 2002; Tully et al., 2007), we used the same induction paradigm in the presence of the $\mathrm{GABA}_{\mathrm{A}}$ receptor antagonist PTX $(100 \mu \mathrm{M})$ (Fig. $5 B)$. Wild-type neurons reliably displayed LTP under these conditions $(p<0.01)$, whereas $\mathrm{PAM}^{+/-}$neurons failed to potentiate. We replicated this finding using a theta burst stimulation induction paradigm, which is reliant on NMDA receptor-mediated postsynaptic calcium signaling (Pan et al., 2009) and field potential recordings (supplemental Fig. S4, available at www.jneurosci.org as supplemental material). This deficit in thalamic afferent LTP cannot be explained by inherent differences in NMDA receptor signaling (supplemental Fig. S5, available at www.jneurosci.org as supplemental material).

GABAergic tansmission can also suppress glutamatergic LTP induction through $\mathrm{GABA}_{\mathrm{B}}$ receptors. $\mathrm{GABA}_{\mathrm{B}}$ receptors are expressed on the dendrites of amygdalar pyramidal neurons and the glutamatergic terminals that innervate them (McDonald et al., 2004). In addition, $\mathrm{GABA}_{\mathrm{B}}$ activation suppresses glutamate release from thalamic and cortical afferent terminals (Pan et al., 2009). To test whether $\mathrm{GABA}_{\mathrm{B}}$ receptors were involved in the PAM ${ }^{+/-}$LTP deficit, we induced LTP using the same action potential pairing paradigm described above in the presence of PTX and the $\mathrm{GABA}_{\mathrm{B}}$ receptor antagonist CGP35348 $(1 \mu \mathrm{M})$ (Fig. 5C). Under these conditions, thalamic afferent synapses were potentiated in wild-type and PAM $^{+/-}$amygdala neurons to similar extents $(p<0.01)$. Collectively, these data provide clear evidence for a synaptic plasticity defintensities).
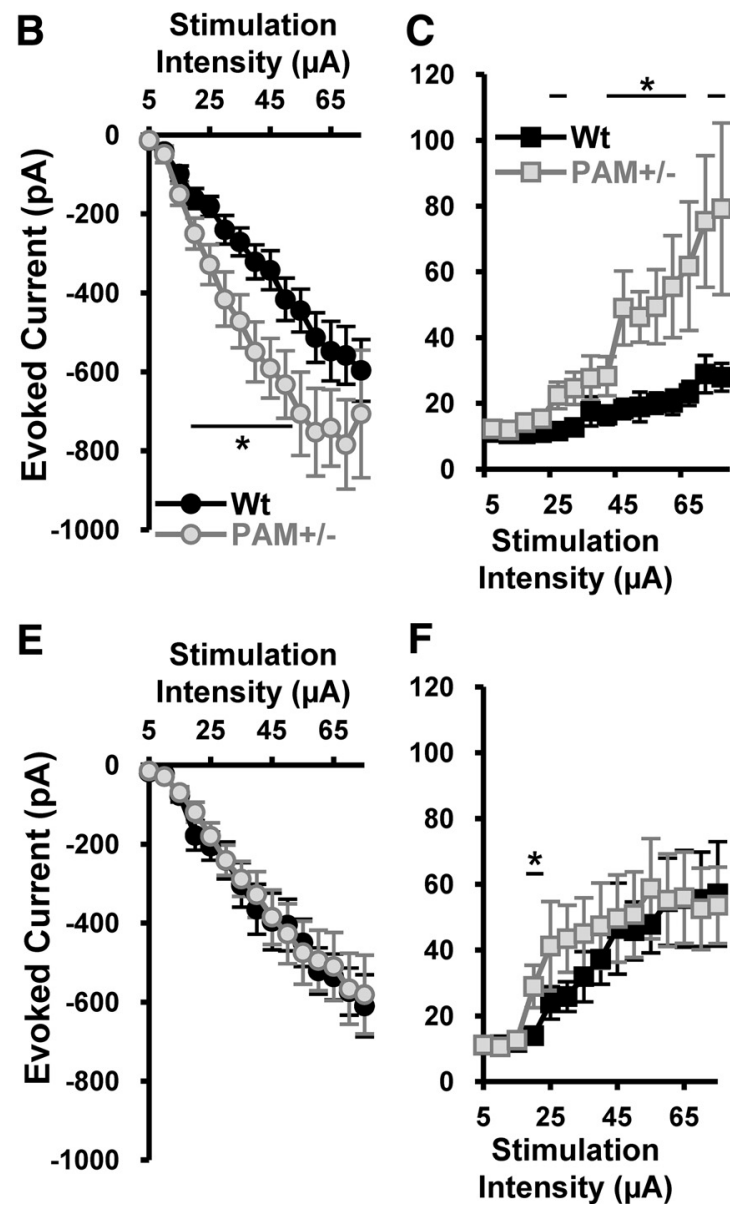

Figure 6. Baseline synaptic efficacy is enhanced at thalamic but not at cortical inputs to the PAM ${ }^{+/-}$lateral nucleus. Recordings of current responses $\left(V_{\text {holding }}=-55 \mathrm{mV}\right.$ ) to graded intensities of single stimuli applied to thalamic and cortical afferent pathways of wild-type (Wt) and PAM ${ }^{+/-}$lateral amygdala slices. Responses consisted of a monosynaptic glutamatergic inward epict pyramidal neuron responses to thalamic $(\boldsymbol{A})$ and cortical $(\boldsymbol{D})$ stimulation. $\boldsymbol{B}, \boldsymbol{E}$, Amplitude of evoked monosynaptic inward/

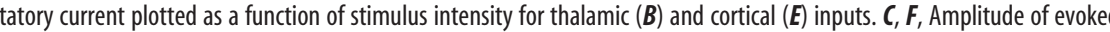
$n=9 \mathrm{Wt}, 11 \mathrm{PAM}^{+/-}$; cortical: $n=8 \mathrm{Wt}, 10 \mathrm{PAM}^{+/-} .^{*} p<0.05$, compared with Wt (unpaired $t$ test at individual stimulation

icit at amygdalar afferent synapses that is reliant on GABAergic transmission and correlates with the fear learning and memory deficit of $\mathrm{PAM}^{+/-}$mice.

\section{Input-specific synaptic enhancement in the}

PAM $^{+/-}$amygdala

We assessed the balance of excitation and inhibition at pathwayspecific afferent synapses in the amygdala by stimulating thalamic or cortical inputs and recording current responses in pyramidal neurons of the lateral nucleus. Interneurons of the amygdala mediate disynaptic feedforward inhibition (Szinyei et al., 2000; Bissiere et al., 2003; Sah et al., 2003; Bauer and Ledoux, 2004; Shin et al., 2006) and contribute a GABAergic outward current that follows the monosynaptic glutamatergic inward current. We adjusted the holding potential to $-55 \mathrm{mV}$ to observe both of these currents in a single trace and generated inputoutput curves for thalamic and cortical input pathways (Fig. 6). Both inward and outward current amplitudes increased with stimulation strength in both genotypes. For thalamic inputs, $\mathrm{PAM}^{+/-}$inward current amplitudes were enhanced compared with wild type at stimulation intensities between 25 and $45 \mu \mathrm{A}$ 


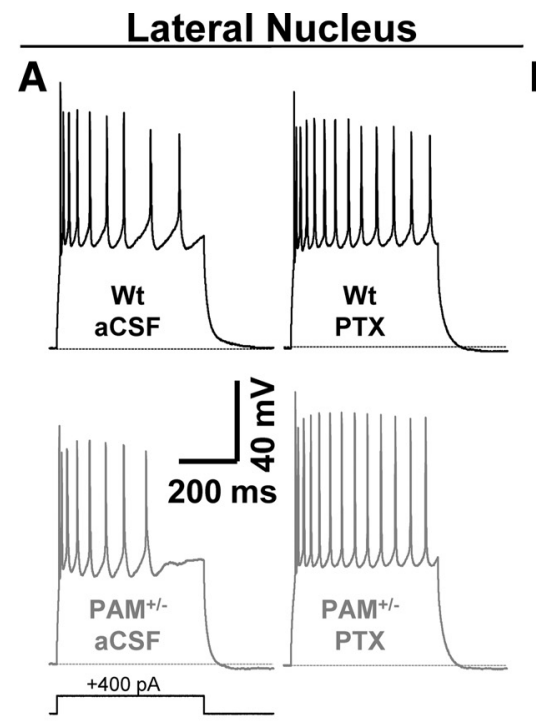

B
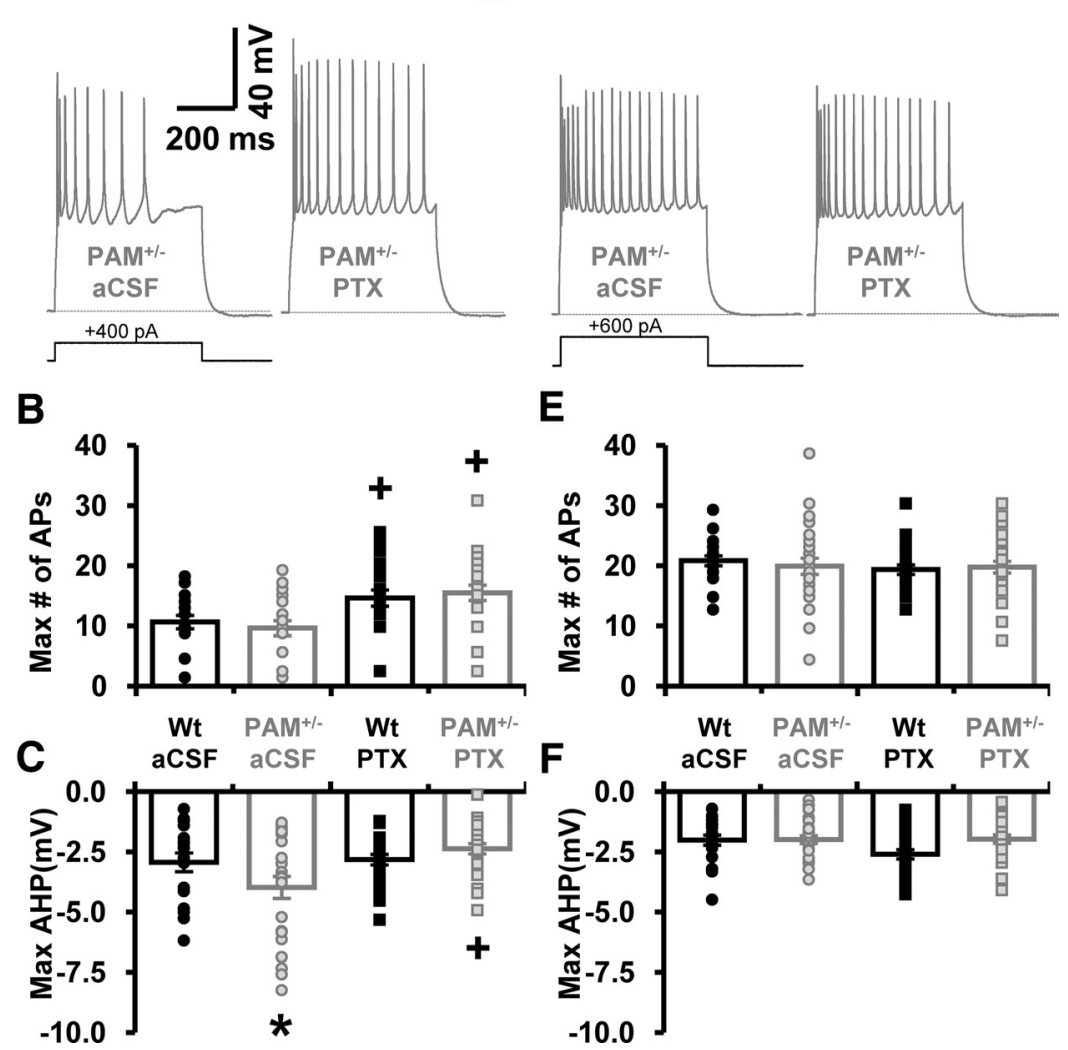

E
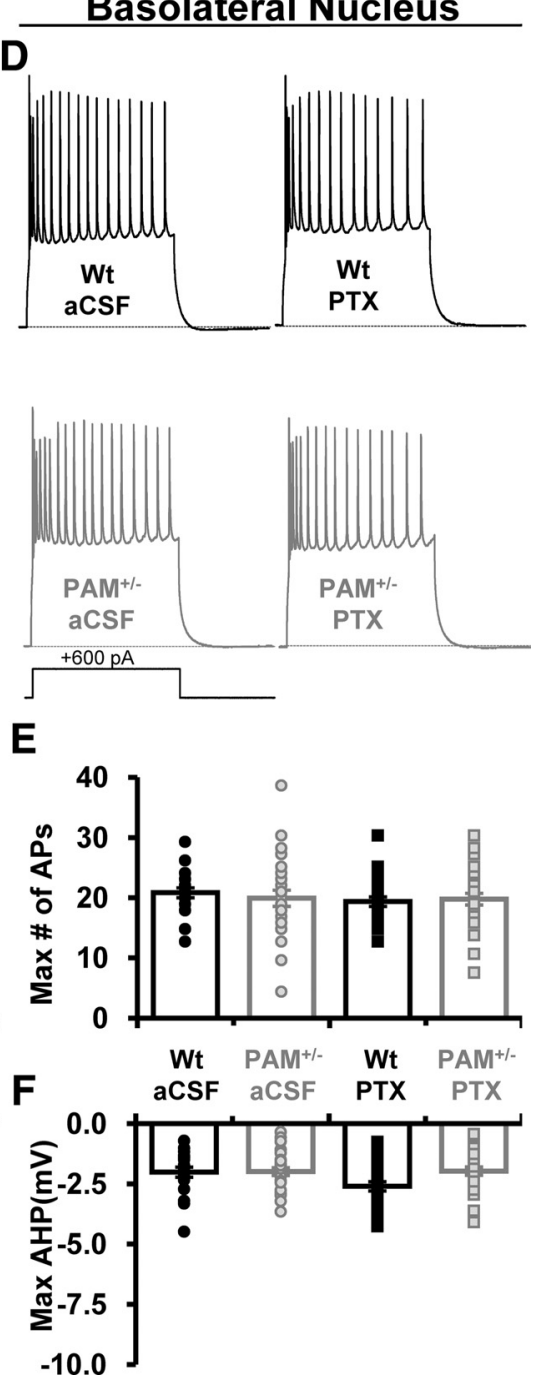

Basolateral Nucleus

Figure 7. Active membrane properties of $\mathrm{PAM}^{+/-}$amygdalar pyramidal neurons are mostly intact but show subtle signs of hyperexcitability. A series of depolarizing 500 ms current steps were applied to wild-type (Wt) and PAM ${ }^{+/-}$pyramidal neurons in the presence and absence of PTX (100 $\mu \mathrm{M}) . \boldsymbol{A}, \boldsymbol{D}$, Representative active membrane voltage responses recorded in control solution (aCSF; left) and in the presence of PTX (right). Insets below indicate current step amplitude corresponding to displayed voltage traces. $\boldsymbol{B}, \boldsymbol{E}$, Action potentials (APs) elicited by current steps were counted, and the maximum numbers of APs are plotted by genotype and treatment condition for lateral $\left(\boldsymbol{B} ; n=17 \mathrm{Wt}, 22 \mathrm{PAM}^{+/-}\right)$and basolateral $\left(\boldsymbol{E} ; n=24 \mathrm{Wt}, 26 \mathrm{PAM}^{+/-}\right)$nuclei pyramidal neurons. Scatter points represent values for individual neurons, and bars represent group means with SEs. C, F, Peak amplitudes of the AHPs that occurred at the offset of each step were measured, and the maximum value for each neuron is plotted by genotype and treatment condition for lateral $(\boldsymbol{C})$ and basolateral $(\boldsymbol{F})$ nucleus pyramidal neurons. ${ }^{*} p<0.05$, compared with Wt within treatment; ${ }^{+} p<0.05$, compared with aCSF within genotype (two-way ANOVA, Bonferroni-corrected pairwise comparisons).

(Fig. 6A-C). $\mathrm{PAM}^{+/-}$outward currents were significantly larger over an even wider range of stimulation intensities. For cortical inputs, wild-type and PAM ${ }^{+/-}$inward current amplitudes were identical over the full stimulation ladder, and $\mathrm{PAM}^{+/-}$outward currents were significantly larger at only one stimulation intensity (Fig. 6D-F). These data demonstrate enhancement of afferent synaptic efficacy and feedforward inhibition in the $\mathrm{PAM}^{+/-}$ lateral amygdala that is specific to the thalamic pathway.

\section{Subtle signs of hyperexcitability}

in the PAM ${ }^{+/-}$amygdala also implicate GABA

Alterations in the firing properties or synaptic organization of amygdalar neurons could influence postsynaptic and presynaptic responses to LTP induction, thus contributing to the LTP deficit observed in $\mathrm{PAM}^{+/-}$mice. The low-dose effect of diazepam on anxiety-like behavior in $\mathrm{PAM}^{+/-}$mice (Fig. 1) and the hypersensitivity of $\mathrm{PAM}^{+/-}$mice to pentylenetetrazol (Bousquet-Moore et al., 2010) suggested that GABAergic inhibition was abnormal. With this in mind, we recorded the membrane and synaptic activities of pyramidal neurons in the lateral and basolateral nuclei of the amygdala in aCSF in the presence and absence of PTX.

We began these studies by measuring passive and active membrane properties. In current-clamp mode, wild-type and $\mathrm{PAM}^{+/-}$amygdala neurons were injected with a series of negative and positive current steps (Fig. 7). Passive membrane properties were derived from voltage responses to negative current steps and yielded no significant genotypic differences (supplemental Tables S3, S4, available at www.jneurosci.org as supplemental material). Positive current steps induced action potentials with similar kinetics in wild-type and $\mathrm{PAM}^{+/-}$ amygdalar pyramidal neurons. Current steps of increasing amplitude were applied until the numbers of action potentials declined because of depolarizationinduced inactivation of voltage-gated $\mathrm{Na}^{+}$channels. The maximum numbers of action potentials fired in response to a single current step by wild-type and $\mathrm{PAM}^{+/-}$neurons in aCSF were similar in the lateral nucleus (Fig. $7 B$ ). PTX increased the maximum number of action potentials in wild-type and $\mathrm{PAM}^{+/-}$neurons. However, this enhancement occurred over a broader range of current steps in $\mathrm{PAM}^{+/-}$neurons compared with wild-type (supplemental Fig. S6 $A, B$, available at www. jneurosci.org as supplemental material). In the basolateral nucleus, the number of action potentials fired was about twofold higher than in the lateral nucleus for both genotypes in aCSF (Fig. $7 B, E$ ), and the addition of PTX did not alter the maximum number of action potentials fired in either genotype. Under aCSF conditions, $\mathrm{PAM}^{+/-}$neurons tended to inactivate earlier than their wild-type controls, and this difference was abolished in the presence of PTX (supplemental Fig. S7 $A, B$, available at www.jneurosci.org as supplemental material).

After termination of the current step, an afterhyperpolarization (AHP) of the membrane potential was often observed (supplemental Figs. S6E, S7E, arrow, available at www.jneurosci.org as supplemental material). In the lateral nucleus under control conditions, $\mathrm{PAM}^{+/-}$neurons displayed larger maximum AHP amplitudes than wild-type neurons $(p<0.05)$ (Fig. 7C). With the addition of PTX, PAM ${ }^{+/-}$AHPs were significantly reduced whereas wild-type AHPs remained unchanged $(p<0.001)$. In the basolateral nucleus, no differences were observed between 
genotypes or treatment conditions (Fig. $7 F$ ). However, AHP values plotted as a function of current step amplitude revealed a twofold enhancement of the AHP in wild-type neurons with PTX, and this effect of PTX was not observed in $\mathrm{PAM}^{+/-}$neurons (supplemental Fig. $\mathrm{S} 7 C, D$, available at www.jneurosci.org as supplemental material). Collectively, these data identify subtle but significant signs of membrane hyperexcitability, including enhanced action potential firing and impaired AHP, in both the lateral and basolateral nuclei of $\mathrm{PAM}^{+/-}$mice.

We next examined the status of fast glutamatergic signaling in $\mathrm{PAM}^{+/-}$ amygdala neurons (Fig. 8). Using the same design as in the previous experiment, we compared sEPSC in wild-type and $\mathrm{PAM}^{+/-}$amygdala neurons in control and PTX conditions. Under control conditions, sEPSC frequency was higher in $\mathrm{PAM}^{+/-}$than in wild-type neurons $(p<0.05)$ (Fig. 8A,B). PTX reduced the frequency and amplitude of sEPSCs in the lateral nucleus and abolished the $\mathrm{PAM}^{+/-}$enhancement in frequency. The opposite was observed in the basolateral nucleus wherein PTX increased the sEPSC frequency $(p<0.001)$ and amplitude $(p<0.05)$ similarly in wild-type and PAM $^{+/-}$neurons (Fig. $8 A, B$ ). These data suggest that the membrane and baseline excitatory synaptic properties of $\mathrm{PAM}^{+/-}$ amygdala neurons are essentially intact with signs of hyperexcitability in PAM $^{+/-}$ lateral nucleus neurons that are GABA dependent.

GABAergic transmission is enhanced in the PAM $^{+/-}$amygdala

Enhanced behavioral sensitivity to lowdose diazepam and the effects of PTX on amygdala neuronal input and output strongly suggest that GABAergic inhibition is perturbed in the PAM $^{+1-}$ brain. To test this hypothesis directly, we recorded GABAergic activity in wild-type and $\mathrm{PAM}^{+/-}$lateral nucleus neurons (Fig. 9). The addition of TTX $(1 \mu \mathrm{M})$ blocked action potential-mediated GABAergic activity and left only activityindependent mIPSCs (supplemental Fig. S8 A, available at www.jneurosci.org as supplemental material). mIPSCs recorded from $\mathrm{PAM}^{+1-}$ neurons displayed increased frequencies $(p<0.001)$ and amplitudes $(p<0.001)$ compared with those recorded from the wild-type lateral nucleus (Fig. 9A). Enhanced frequency of $\mathrm{PAM}^{+/-}$activity-independent GABAergic events in the lateral nucleus could result from an increase in release probability or synapse number. To distinguish these possibilities, we evoked inhibitory signals via local stimulation (Marowsky et al., 2005) and increased the stimulation strength to achieve maximal responses (Fig. 9B). The charges of evoked synaptic responses were significantly larger than wild-type responses across the full range of stimulation intensities and at their maximal values. This difference in charge was evidently contributed by a combination of peak current amplitude and fast decay time (supplemental Fig. S8 B-E, available at www.jneurosci.org as supplemental material); however, these particular parameters were not significantly different between genotypes. Charge signified the absolute number of $\mathrm{Cl}^{-}$ions that pass in response to a given stimulus, and its enhancement in the $\mathrm{PAM}^{+/-}$lateral nucleus supports either a greater number of inhibitory synapses or enhanced release probability.

We then adjusted the stimulation strength to that which evoked a half-maximal response and recorded current responses to paired pulses (Fig. 9C). There was no statistical difference in paired-pulse ratio between wild-type and $\mathrm{PAM}^{+/-}$at any of the three interpulse intervals tested, suggesting that the enhanced GABAergic activity observed in the $\mathrm{PAM}^{+/-}$lateral amygdala does not result from a difference in release probability, but rather from an increase in the number of GABAergic synapses. Response to paired pulses, as a function of interpulse interval, depended on genotype $(p<0.05)$. The complicated circuitry of the interneuronal network makes specific interpretation of this result 


\section{Lateral Nucleus}
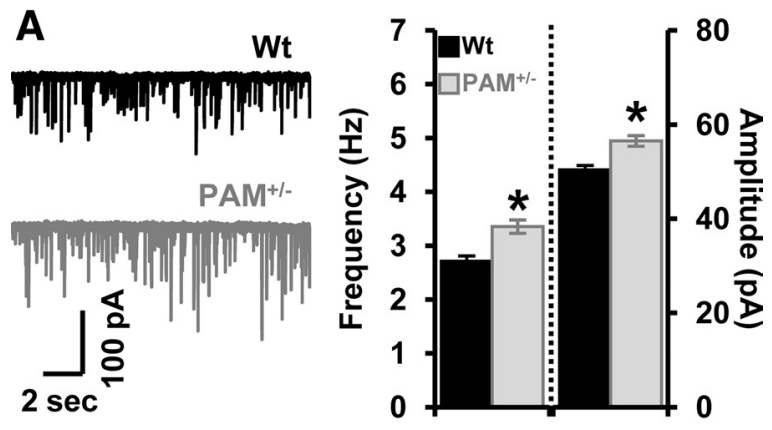

B
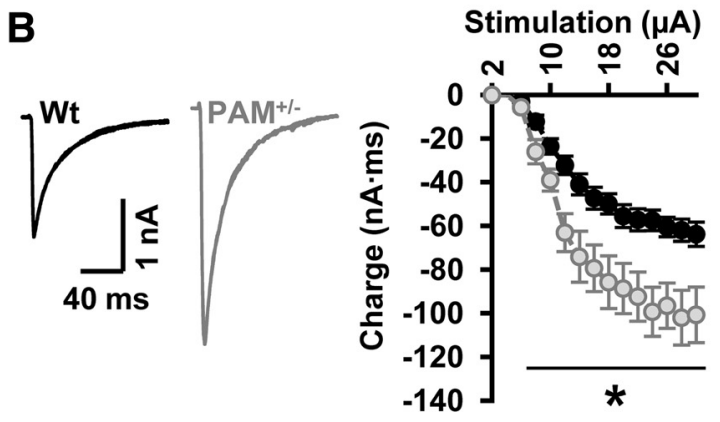

C
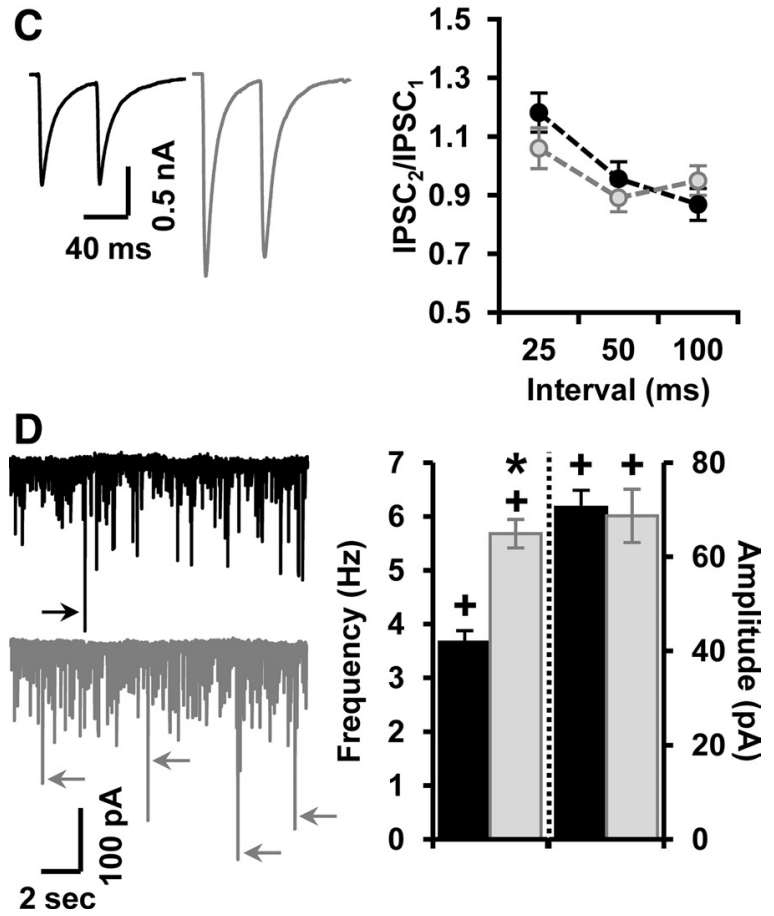

Figure 9. GABAergic signaling is enhanced in the PAM ${ }^{+/-}$lateral nucleus. Wild-type (Wt) and PAM ${ }^{+/-}$pyramidal neurons in the lateral nucleus were dialyzed with a high $\left[\mathrm{Cl}^{-}\right]$ containing pipette solution, and IPSCs were recorded under glutamatergic blockade. $A$, mIPSCS were recorded in the presence of $1 \mu \mathrm{M}$ TTX. Representative current traces depicting mIPSCS recorded from Wt and PAM ${ }^{+/-}$pyramidal neurons (left) are shown. Mean mIPSC frequency and amplitude are plotted for both genotypes (right; $n=28 \mathrm{Wt}, 25 \mathrm{PAM}^{+/-} ; 37$ events per neuron). $\boldsymbol{B}$, Local stimulation elicited "evoked" IPSCs in Wt and PAM ${ }^{+/-}$neurons only in the absence of TTX. Two superimposed representative current traces from each genotype in response to a $20 \mu$ A single stimulus are shown (left). Charge (the integral of current) was used as a measure of synaptic strength and is plotted as a function of stimulation intensity (right; $n=$ $21 \mathrm{Wt}, 16 \mathrm{PAM}^{+/-}$). ${ }^{*} p<0.05$, compared with Wt (unpaired $t$ tests at individual stimulus intensities). C, Paired pulses were applied under the same conditions as in $\boldsymbol{B}$. Averaged traces for each genotype depict representative current responses to paired pulses evoked at an intensity that elicited half-maximal responses for individual neurons (left). Ratios for both genotypes are difficult, but it is clear that activity-dependent inhibitory signals from the interneuronal network are perturbed in $\mathrm{PAM}^{+1-}$ mice.

To determine whether there is an activity-dependent component of GABAergic enhancement in the $\mathrm{PAM}^{+/-}$amygdala, we recorded sIPSCs in the absence of TTX. We kept glutamatergic transmission blocked to ensure isolation of interneuronal network activity. As expected, sIPSC frequency and amplitude were significantly increased compared with those of mIPSCs caused by the addition of large activity-dependent GABAergic events (Fig. $9 D$, arrows). Although $\mathrm{PAM}^{+/-}$neurons appeared to display a larger increase in frequency than wild-type neurons, ANOVA found no significant interaction between TTX condition and genotype. In the basolateral nucleus, sIPSC frequency was threefold higher than in the lateral nucleus (supplemental Fig. S9, available at www.jneurosci.org as supplemental material). These results correlate with the substantial increase in GAD67 immunoreactivity, presumably representing GABAergic synapses, between the lateral and basolateral nuclei (Fig. 4; supplemental Fig. S3, available at www.jneurosci.org as supplemental material). sIPSCs recorded from $\mathrm{PAM}^{+/-}$neurons displayed enhanced frequencies $(p<0.05)$ and reduced amplitudes $(p<0.001)$. Collectively, these data provide clear evidence for enhanced GABAergic transmission in the $\mathrm{PAM}^{+/-}$amygdala.

\section{Discussion}

This study identifies neurophysiological correlates in the amygdala that may contribute to the behavioral abnormalities observed in PAM-deficient animals. We have previously shown that half the normal amount of PAM is insufficient to support normal physiology and that heterozygous mice exhibit an anxiety-like phenotype (Czyzyk et al., 2005; Bousquet-Moore et al., 2009, 2010). Data presented here expand the $\mathrm{PAM}^{+/-}$behavioral phenotype to include learned fear, characterize cellular PAM expression in the amygdala, and demonstrate signs of enhanced inhibition that likely contribute to the observed deficit in amygdalar afferent synaptic plasticity. Our data indicate that PAM heterozygosity affects several neuronal properties and neurotransmitter systems in the amygdala (Fig. 10), which is consistent with the multiple modulatory/signaling pathways in which neuropeptides play a role. Our results emphasize the importance and sensitivity of peptidergic pathways in mammalian amygdaladependent emotions and behaviors.

\section{Integrating the $\mathrm{PAM}^{+/-}$behavioral and physiological phenotypes}

Anxiety and fear responses

Our results show that $\mathrm{PAM}^{+/-}$mice display anxiety-like behaviors and are deficient in contextual and cued fear conditioning. These findings were unexpected because "anxious" mice often show enhanced fear responses (Korte and De Boer, 2003). Over the years, evidence has accrued that projections from the lateral bed nucleus of stria terminalis mediate certain types of anxiety and stress responses, whereas the medial central nucleus of the

$\leftarrow$

plotted for 25, 50, and $100 \mathrm{~ms}$ intervals (right; $n=16 \mathrm{Wt}, 13$ PAM $^{+/-}$). D, sIPSCs were recorded from Wt and PAM ${ }^{+/-}$neurons in the absence of TTX and local stimulation. Representative current traces depicting sIPSCs recorded from Wt and PAM ${ }^{+/-}$pyramidal neurons (left) are shown. Arrows indicate putative action potential-dependent GABAergic events. IPSC frequency and amplitude are plotted for both genotypes (right; $n=25 \mathrm{Wt}_{1} 21 \mathrm{PAM}^{+/-} ; 36$ events per neuron). ${ }^{*} p<0.05$, compared with $\mathrm{Wt}^{+}{ }^{+} p<0.05$, compared with mIPSC value within genotype (ANOVA, Bonferroni-corrected pairwise comparisons for mIPSC and sIPSC data). 
amygdala controls phasic fear (Iwata et al., 1986; Ledoux et al., 1988; Hitchcock and Davis, 1991). Recent studies indicate that anxiety and learned fear may differ in a number of attributes that include behavioral responses, anatomical substrates, and transmitter/signaling mechanisms (Davis et al., 2010). The consequences of PAM haploinsufficiency may differentially affect these pathways/systems, resulting in the observed dissociated fear phenotype. Indeed, there are neuropeptide receptor knock-out models with dissociated fear phenotypes (Shumyatsky et al., 2002; Zeng et al., 2007). Thus, the $\mathrm{PAM}^{+/-}$fear phenotype may signify distinct neuropeptidergic systems in innate and learned fear pathways.

\section{Fear learning/memory and LTP}

The disruption of synaptic plasticity observed at the thalamic inputs to the amygdala strongly correlates with the fear learning and memory phenotype of $\mathrm{PAM}^{+/-}$mice, and it may serve as the neurophysiological basis for these behavioral impairments. Deficiencies at both short $(1 \mathrm{~h})$ and long $(24 \mathrm{~h})$ time points in both cued and contextual testing demonstrate impaired formation and/or consolidation of associative emotional memory. It is clear, however, that $\mathrm{PAM}^{+/-}$mice are capable of learning; deficiencies in fear-potentiated startle were observed at the low and not the high shock intensity. This result is quite striking since both genotypes display similar levels of behavioral reactivities and sensitivities to a wide range of footshock intensities that included those used in conditioning. One explanation is that enhanced GABAergic inhibition in the $\mathrm{PAM}^{+/-}$amygdala sets a higher threshold for plasticity induction during training. This notion is supported by evidence for enhanced GABAergic activity in the PAM ${ }^{+/-}$amygdala and the ability of complete GABAergic blockade to eliminate the LTP deficit in $\mathrm{PAM}^{+/-}$mice. Future experiments will focus on determining how specific enhancements in GABAergic inhibition may contribute to the fear learning and memory deficit of $\mathrm{PAM}^{+/-}$mice.

Anxiety-like behaviors and GABA

$\mathrm{PAM}^{+1-}$ mice display anxiety-like behaviors in the zero maze, and the alleviation of these responses with diazepam provides pharmacological validation for the behavior. The anxiety-like responses of the heterozygotes may be attributable to a reduction in bioactivity of one or several PAM-requiring neuropeptides that normally exert anxiolytic actions. Many neuropeptides modulate the excitatory-inhibitory balance by regulating pyramidal neuron and interneuron membrane activities (Fig. 10). The prominent enhancement in GABAergic activity in the $\mathrm{PAM}^{+/-}$ amygdala signifies disruption of that balance. The augmented GABAergic tone may render the $\mathrm{PAM}^{+/-}$brain susceptible to inhibitory limitation during stressful behavioral tasks such as the elevated-zero maze (Martijena et al., 2002;Stork et al., 2002) by endogenous hormones/neuromodulators (e.g., catecholamines, glucocorticoids) (Marowsky et al., 2005; Duvarci and Pare, 2007; Tully et al., 2007). This is also consistent with hypersensitivity of $\mathrm{PAM}^{+/-}$mice to diazepam in the elevated-zero maze and penty- lenetetrazol during seizure induction (Bousquet-Moore et al., 2010). Alternatively, changes in the functional expression of GABA and/or benzodiazepine receptors were not assessed in these experiments and could contribute to the anxiety-like phenotype of $\mathrm{PAM}^{+/-}$mice. It should be emphasized that anxiety is a complex condition that is mediated by a variety of brain regions that, at least, include the frontal cortex, bed nucleus of stria terminalis, and the amygdala (LeDoux, 2000, 2007; Maren and Quirk, 2004; Pare et al., 2004; Kim and Jung, 2006; Davis et al., 2010). Therefore, we cannot draw any definitive conclusions regarding the physiological basis for the $\mathrm{PAM}^{+/-}$anxiety-like phenotype and sensitivity to diazepam from these studies alone.

\section{$\mathrm{PAM}^{+/-}$as a model for insufficient amidation}

Approximately half of all neuropeptides are amidated, and amidation can be rate limiting under physiological conditions (Merkler, 1994) and in PAM haploinsufficiency (BousquetMoore et al., 2009). Insufficient amidation and the resulting reduction in bioactive anxiolytic peptides would be the simplest explanation for how PAM haploinsufficiency might affect behavior. The prototypical example is neuropeptide Y (NPY), one of the most abundant neuropeptides in the mammalian brain. NPY, which has a C-terminal tyrosine amide (Eipper et al., 1992), suppresses anxiety-like behavior and learned fear responses when injected directly into the basolateral complex (Gutman et al., 2008). However, relative levels of amidated NPY are unchanged in the PAM ${ }^{+/-}$brain (Czyzyk et al., 2005), and direct physiological effectors of NPY signaling (e.g., passive membrane properties of pyramidal neurons) (Sosulina et al., 2008) are unaltered in the PAM $^{+/-}$amygdala (Fig. 10, right). Therefore, it is unlikely that changes in NPY signaling dominate the $\mathrm{PAM}^{+/-}$phenotype.

Different Gly-extended precursors have varied affinities for the PHM catalytic core. For example, thyrotropin-releasing hor- 
mone (TRH) terminates with proline amide (Eipper et al., 1992), and its Gly-extended precursor (TRH-Gly) is a particularly poor substrate for amidation. Consistent with this, there is an abundance of TRH-Gly in the amygdala compared with high PAMexpressing areas like the hypothalamus $\left(\mathrm{PAM}^{+/-}\right.$mice are euthyroid) (Bousquet-Moore et al., 2009), and PAM heterozygosity also impairs amidation of TRH in the amygdala (E. A. Nillni, unpublished data). Since TRH signaling in the amygdala is involved in mediating anxiety-like behavior (Thompson and Rosen, 2000; Yarbrough et al., 2007; Zeng et al., 2007), particularly in the elevated-plus maze (Zeng et al., 2007; GutierrezMariscal et al., 2008), the mechanism how TRH may influence amygdala physiology is an important avenue for future study. For example, TRH enhances $\mathrm{GABA}_{\mathrm{A}}$ receptor-mediated transmission in the basolateral complex (E. D. Gaier, B. A. Eipper, and R. E. Mains, unpublished data) (Fig. 10), which may underlie its reported anxiolytic effects and relate to the genotypic differences we observed. However, TRH signaling has no effect on learned fear responses (Thompson and Rosen, 2000; Zeng et al., 2007), making it unlikely that deficient TRH signaling could solely account for the $\mathrm{PAM}^{+/-}$phenotype.

\section{Nonenzymatic roles of PAM}

Regulating the secretory pathway

PAM heterozygosity could have effects outside of a reduction in amidating activity. Overexpression of PAM in a pituitary corticotropic cell line reorganizes the actin cytoskeleton, impairs regulated secretion of amidated and nonmodified peptides, and impairs normal secretory granule maturation and localization (Ciccotosto et al., 1999). These effects are mediated through the cytosolic domain of PAM (Alam et al., 2001). Therefore, it is plausible that limitations in PAM could have the opposite effect and enhance stimulus-evoked secretion. In this sense, increased anxiogenic peptide signaling would account for the $\mathrm{PAM}^{+/-}$ phenotypes. Potential candidates include cholecystokinin (CCK) (Fendt et al., 1995; Chen et al., 2006) and corticotropin-releasing hormone/factor (synthesized in the central nucleus) (Bale and Vale, 2004), both of whose signaling increases GABAergic transmission in the amygdala (Nie et al., 2004; Chung and Moore, 2007, 2009). Regulation of GABAergic transmission is clearly a major modulatory target of amygdalar neuropeptides (Fig. 10, left). Our findings in the PAM ${ }^{+/-}$amygdala suggest net enhancement of that signaling, which supports a nonamidationdependent mechanism for PAM haploinsufficiency.

Gastrin-releasing peptide (GRP), another amidated peptide (Baldwin et al., 2007), is expressed and secreted by pyramidal neurons of the basolateral complex (Fig. 10). GRP signaling suppresses LTP by enhancing the excitability of and the GABA release from local interneurons on which the GRP receptor is expressed (Shumyatsky et al., 2002). However, contradictory evidence using GRP receptor antagonist infusion into the amygdala of rats (Roesler et al., 2004; Mountney et al., 2006, 2008; Bedard et al., 2007) makes it difficult to predict the role of GRP signaling in modulating amygdala neurophysiology and amygdaladependent behaviors. Thus, altered GRP signaling in the $\mathrm{PAM}^{+/-}$brain may contribute to physiological and behavioral differences we observed.

\section{Copper metabolism}

It is clear that copper metabolism is intricately tied with PAM function and vice versa. Copper can regulate the cleavage and recycling of PAM (De et al., 2007) and could therefore have important effects on nuclear signaling. Some $\mathrm{PAM}^{+/-}$behavioral phenotypes can be rescued with dietary copper supplementation of PAM $^{+/-}$mice and mimicked with mild copper depletion in wild-type mice (Bousquet-Moore et al., 2009, 2010). Anxiety-like behavior falls into this category, whereas seizure sensitivity does not. On the other hand, PAM heterozygosity could mediate its effects by altering copper signaling. Copper is secreted by neurons and can suppress NMDA receptor function through a nitric oxide-dependent mechanism (Schlief et al., 2006). Nitric oxide signaling is also required for auditory fear conditioning and LTP at thalamic afferent amygdalar synapses (Schafe et al., 2005; Ota et al., 2008). Therefore, copper signaling may play a role in limiting synaptic plasticity in the $\mathrm{PAM}^{+/-}$amygdala.

$\mathrm{PAM}^{+/-}$animals exhibit impairments involving several interdependent organ systems, and there is evidence for both amidation- and nonamidation-related mechanisms in explaining their behavioral and physiological deficits. These layers of complexity likely reflect the multifaceted regulation of peptide signaling and the plethora of roles peptides play in physiology and pathophysiology. Clearly, peptidergic signaling relies on normal PAM function. Peptides are a promising avenue of novel therapeutics in psychiatric treatments of anxiety disorders (Mathew et al., 2008). Pursuing the study of how dietary, pharmacological, and genetic influencers of PAM function can alter physiology, and behavior brings us closer to identifying how peptidergic signaling pathways can serve as targets for clinical intervention.

\section{References}

Alam MR, Steveson TC, Johnson RC, Back N, Abraham B, Mains RE, Eipper BA (2001) Signaling mediated by the cytosolic domain of peptidylglycine alpha-amidating monooxygenase. Mol Biol Cell 12:629-644.

Anagnostaras SG, Josselyn SA, Frankland PW, Silva AJ (2000) Computerassisted behavioral assessment of Pavlovian fear conditioning in mice. Learn Mem 7:58-72.

Baldwin GS, Patel O, Shulkes A (2007) Phylogenetic analysis of the sequences of gastrin-releasing peptide and its receptors: biological implications. Regul Pept 143:1-14.

Bale TL, Vale WW (2004) CRF and CRF receptors: role in stress responsivity and other behaviors. Annu Rev Pharmacol Toxicol 44:525-557.

Bauer EP, Ledoux JE (2004) Heterosynaptic long-term potentiation of inhibitory interneurons in the lateral amygdala. J Neurosci 24:9507-9512.

Bauer EP, Schafe GE, Ledoux JE (2002) NMDA receptors and L-type voltage-gated calcium channels contribute to long-term potentiation and different components of fear memory formation in the lateral amygdala. J Neurosci 22:5239-5249.

Bedard T, Mountney C, Kent P, Anisman H, Merali Z (2007) Role of gastrin-releasing peptide and neuromedin $\mathrm{B}$ in anxiety and fear-related behavior. Behav Brain Res 179:133-140.

Bissiere S, Humeau Y, Luthi A (2003) Dopamine gates LTP induction in lateral amygdala by suppressing feedforward inhibition. Nat Neurosci 6:587-592.

Bousquet-Moore D, Ma XM, Nillni EA, Czyzyk TA, Pintar JE, Eipper BA, Mains RE (2009) Reversal of physiological deficits caused by diminished levels of peptidylglycine alpha-amidating monooxygenase by dietary copper. Endocrinology 150:1739-1747.

Bousquet-Moore D, Prohaska JR, Nillni EA, Czyzyk T, Wetsel WC, Mains RE, Eipper BA (2010) Interactions of peptide amidation and copper: novel biomarkers and mechanisms of neural dysfunction. Neurobiol Dis 37:130-140.

Caron KM, Smithies O (2001) Extreme hydrops fetalis and cardiovascular abnormalities in mice lacking a functional Adrenomedullin gene. Proc Natl Acad Sci U S A 98:615-619.

Chen Q, Nakajima A, Meacham C, Tang YP (2006) Elevated cholecystokininergic tone constitutes an important molecular/neuronal mechanism for the expression of anxiety in the mouse. Proc Natl Acad Sci U S A 103:3881-3886.

Chung L, Moore SD (2007) Cholecystokinin enhances GABAergic inhibitory transmission in basolateral amygdala. Neuropeptides 41:453-463.

Chung L, Moore SD (2009) Cholecystokinin excites interneurons in rat basolateral amygdala. J Neurophysiol 102:272-284. 
Ciccotosto GD, Schiller MR, Eipper BA, Mains RE (1999) Induction of integral membrane PAM expression in AtT-20 cells alters the storage and trafficking of POMC and PC1. J Cell Biol 144:459-471.

Czyzyk TA, Ning Y, Hsu MS, Peng B, Mains RE, Eipper BA, Pintar JE (2005) Deletion of peptide amidation enzymatic activity leads to edema and embryonic lethality in the mouse. Dev Biol 287:301-313.

Davis M (1990) Animal models of anxiety based on classical conditioning: the conditioned emotional response (CER) and the fear-potentiated startle effect. Pharmacol Ther 47:147-165.

Davis M, Walker DL, Miles L, Grillon C (2010) Phasic vs sustained fear in rats and humans: role of the extended amygdala in fear vs anxiety. Neuropsychopharmacology 35:105-135.

De M, Ciccotosto GD, Mains RE, Eipper BA (2007) Trafficking of a secretory granule membrane protein is sensitive to copper. J Biol Chem 282:23362-23371.

Duvarci S, Pare D (2007) Glucocorticoids enhance the excitability of principal basolateral amygdala neurons. J Neurosci 27:4482-4491.

Eipper BA, Mains RE (1988) Peptide alpha-amidation. Annu Rev Physiol 50:333-344.

Eipper BA, Glembotski CC, Mains RE (1983) Bovine intermediate pituitary alpha-amidation enzyme: preliminary characterization. Peptides 4:921-928.

Eipper BA, Stoffers DA, Mains RE (1992) The biosynthesis of neuropeptides: peptide alpha-amidation. Annu Rev Neurosci 15:57-85.

Fendt M, Koch M, Kungel M, Schnitzler HU (1995) Cholecystokinin enhances the acoustic startle response in rats. Neuroreport 6:2081-2084.

Grove M, Demyanenko G, Echarri A, Zipfel PA, Quiroz ME, Rodriguiz RM, Playford M, Martensen SA, Robinson MR, Wetsel WC, Maness PF, Pendergast AM (2004) ABI2-deficient mice exhibit defective cell migration, aberrant dendritic spine morphogenesis, and deficits in learning and memory. Mol Cell Biol 24:10905-10922.

Gutierrez-Mariscal M, de Gortari P, Lopez-Rubalcava C, Martinez A, JosephBravo P (2008) Analysis of the anxiolytic-like effect of TRH and the response of amygdalar TRHergic neurons in anxiety. Psychoneuroendocrinology 33:198-213.

Gutman AR, Yang Y, Ressler KJ, Davis M (2008) The role of neuropeptide Y in the expression and extinction of fear-potentiated startle. J Neurosci 28:12682-12690.

Hitchcock JM, Davis M (1991) Efferent pathway of the amygdala involved in conditioned fear as measured with the fear-potentiated startle paradigm. Behav Neurosci 105:826-842.

Iwata J, Ledoux JE, Meeley MP, Arneric S, Reis DJ (1986) Intrinsic neurons in the amygdaloid field projected to by the medial geniculate body mediate emotional responses conditioned to acoustic stimuli. Brain Res 383:195-214.

Kim JJ, Fanselow MS (1992) Modality-specific retrograde amnesia of fear. Science 256:675-677.

Kim JJ, Jung MW (2006) Neural circuits and mechanisms involved in Pavlovian fear conditioning: a critical review. Neurosci Biobehav Rev 30:188-202.

Korte SM, De Boer SF (2003) A robust animal model of state anxiety: fearpotentiated behaviour in the elevated plus-maze. Eur J Pharmacol 463:163-175.

Lanuza E, Moncho-Bogani J, Ledoux JE (2008) Unconditioned stimulus pathways to the amygdala: Effects of lesions of the posterior intralaminar thalamus on foot-shock-induced c-Fos expression in the subdivisions of the lateral amygdala. Neuroscience 155:959-968.

LeDoux J (2007) The amygdala. Curr Biol 17:R868-R874.

Ledoux JE (2000) Emotion circuits in the brain. Annu Rev Neurosci 23:155-184.

Ledoux JE, Iwata J, Cicchetti P, Reis DJ (1988) Different projections of the central amygdaloid nucleus mediate autonomic and behavioral correlates of conditioned fear. J Neurosci 8:2517-2529.

Ledoux JE, Cicchetti P, Xagoraris A, Romanski LM (1990) The lateral amygdaloid nucleus: sensory interface of the amygdala in fear conditioning. J Neurosci 10:1062-1069.

Ma XM, Johnson RC, Mains RE, Eipper BA (2001) Expression of Kalirin, a neuronal GDP/GTP exchange factor of the Trio family, in the central nervous system of the adult rat. J Comp Neurol 429:388-402.

Ma XM, Mains RE, Eipper BA (2002) Plasticity in hippocampal peptidergic systems induced by repeated electroconvulsive shock. Neuropsychopharmacology 27:55-71.
Ma XM, Kiraly DD, Gaier ED, Wang Y, Kim EJ, Levine ES, Eipper BA, Mains RE (2008) Kalirin-7 Is required for synaptic structure and function. J Neurosci 28:12368-12382.

Mains RE, Bloomquist BT, Eipper BA (1991) Manipulation of neuropeptide biosynthesis through the expression of antisense RNA for peptidylglycine alpha-amidating monooxygenase. Mol Endocrinol 5:187-193.

Maltese J-Y, Eipper BA (1992) Developmental expression of peptidylglycine alpha-amidating monooxygenase (PAM) in primary cultures of neonatal rat cardiocytes: a model for studying regulation of PAM expression in the rat heart. Mol Endocrinol 6:1998-2008.

Maren S, Quirk GJ (2004) Neuronal signalling of fear memory. Nat Rev Neurosci 5:844-852.

Marowsky A, Yanagawa Y, Obata K, Vogt KE (2005) A specialized subclass of interneurons mediates dopaminergic facilitation of amygdala function. Neuron 48:1025-1037.

Martijena ID, Rodriguez Manzanares PA, Lacerra C, Molina VA (2002) Gabaergic modulation of the stress response in frontal cortex and amygdala. Synapse 45:86-94.

Mathew SJ, Price RB, Charney DS (2008) Recent advances in the neurobiology of anxiety disorders: implications for novel therapeutics. Am J Med Genet C Semin Med Genet 148:89-98.

McDonald AJ, Mascagni F, Muller JF (2004) Immunocytochemical localization of GABABR1 receptor subunits in the basolateral amygdala. Brain Res 1018:147-158.

Merkler DJ (1994) C-terminal amidated peptides: production by the in vitro enzymatic amidation of glycine-extended peptides and the importance of the amide to bioactivity. Enzyme Microb Technol 16:450-456.

Mountney C, Sillberg V, Kent P, Anisman H, Merali Z (2006) The role of gastrin-releasing peptide on conditioned fear: differential cortical and amygdaloid responses in the rat. Psychopharmacology (Berl) 189:287-296.

Mountney C, Anisman H, Merali Z (2008) Effects of gastrin-releasing peptide agonist and antagonist administered to the basolateral nucleus of the amygdala on conditioned fear in the rat. Psychopharmacology (Berl) 200:51-58.

Muller JF, Mascagni F, McDonald AJ (2003) Synaptic connections of distinct interneuronal subpopulations in the rat basolateral amygdalar nucleus. J Comp Neurol 456:217-236.

Muller JF, Mascagni F, McDonald AJ (2005) Coupled networks of parvalbumin-immunoreactive interneurons in the rat basolateral amygdala. J Neurosci 25:7366-7376.

Muller JF, Mascagni F, McDonald AJ (2006) Pyramidal cells of the rat basolateral amygdala: synaptology and innervation by parvalbuminimmunoreactive interneurons. J Comp Neurol 494:635-650.

Niciu MJ, Ma XM, El Meskini R, Ronnett GV, Mains RE, Eipper BA (2006) Developmental changes in the expression of ATP7A during a critical period in postnatal neurodevelopment. Neuroscience 139:947-964.

Nie Z, Schweitzer P, Roberts AJ, Madamba SG, Moore SD, Siggins GR (2004) Ethanol augments GABAergic transmission in the central amygdala via CRF1 receptors. Science 303:1512-1514.

Ota KT, Pierre VJ, Ploski JE, Queen K, Schafe GE (2008) The NO-cGMPPKG signaling pathway regulates synaptic plasticity and fear memory consolidation in the lateral amygdala via activation of ERK/MAP kinase. Learn Mem 15:792-805.

Pan BX, Dong Y, Ito W, Yanagawa Y, Shigemoto R, Morozov A (2009) Selective gating of glutamatergic inputs to excitatory neurons of amygdala by presynaptic GABAb receptor. Neuron 61:917-929.

Pare D, Quirk GJ, Ledoux JE (2004) New vistas on amygdala networks in conditioned fear. J Neurophysiol 92:1-9.

Phillips RG, Ledoux JE (1992) Differential contribution of amygdala and hippocampus to cued and contextual fear conditioning. Behav Neurosci 106:274-285.

Pogorelov VM, Rodriguiz RM, Insco ML, Caron MG, Wetsel WC (2005) Novelty seeking and stereotypic activation of behavior in mice with disruption of the Datl gene. Neuropsychopharmacology 30:1818-1831.

Porton B, Rodriguiz RM, Phillips LE, Gilbert JW, Feng J, Greengard P, Kao HT, Wetsel WC (2009) Mice lacking synapsin III show abnormalities in explicit memory and conditioned fear. Genes Brain Behav 9:257-268.

Prigge ST, Kolhekar AS, Eipper BA, Mains RE, Amzel LM (1997) Amidation of bioactive peptides: the structure of peptidylglycine $\alpha$-hydroxylating monooxygenase. Science 278:1300-1305.

Prigge ST, Mains RE, Eipper BA, Amzel LM (2000) New insights into copper 
monooxygenases and peptide amidation: structure, mechanism and function. Cell Mol Life Sci 57:1236-1259.

Quirk GJ, Armony JL, Ledoux JE (1997) Fear conditioning enhances different temporal components of tone-evoked spike trains in auditory cortex and lateral amygdala. Neuron 19:613-624.

Rainnie DG, Mania I, Mascagni F, McDonald AJ (2006) Physiological and morphological characterization of parvalbumin-containing interneurons of the rat basolateral amygdala. J Comp Neurol 498:142-161.

Rajagopal C, Stone KL, Francone VP, Mains RE, Eipper BA (2009) Secretory granule to the nucleus: Role of a multiply phosphorylated intrinsically unstructured domain. J Biol Chem 284:25723-25734.

Roesler R, Lessa D, Venturella R, Vianna MR, Luft T, Henriques JA, Izquierdo I, Schwartsmann G (2004) Bombesin/gastrin-releasing peptide receptors in the basolateral amygdala regulate memory consolidation. Eur J Neurosci 19:1041-1045.

Sah P, Faber ES, Lopez De AM, Power J (2003) The amygdaloid complex: anatomy and physiology. Physiol Rev 83:803-834.

Sah P, Westbrook RF, Luthi A (2008) Fear conditioning and long-term potentiation in the amygdala: what really is the connection? Ann N Y Acad Sci 1129:88-95.

Salio C, Lossi L, Ferrini F, Merighi A (2006) Neuropeptides as synaptic transmitters. Cell Tissue Res 326:583-598.

Schafe GE, Bauer EP, Rosis S, Farb CR, Rodrigues SM, Ledoux JE (2005) Memory consolidation of Pavlovian fear conditioning requires nitric oxide signaling in the lateral amygdala. Eur J Neurosci 22:201-211.

Schafer MKH, Stoffers DA, Eipper BA, Watson SJ (1992) Expression of PAM in the rat central nervous system. J Neurosci 12:222-234.

Schlief ML, West T, Craig AM, Holtzman DM, Gitlin JD (2006) Role of the Menkes copper-transporting ATPase in NMDA receptor-mediated neuronal toxicity. Proc Natl Acad Sci U S A 103:14919-14924.

Shaban H, Humeau Y, Herry C, Cassasus G, Shigemoto R, Ciocchi S, Barbieri S, van der PH, Kaupmann K, Bettler B, Luthi A (2006) Generalization of amygdala LTP and conditioned fear in the absence of presynaptic inhibition. Nat Neurosci 9:1028-1035.

Shepherd JK, Grewal SS, Fletcher A, Bill DJ, Dourish CT (1994) Behavioural and pharmacological characterisation of the elevated "zero-maze" as an animal model of anxiety. Psychopharmacology (Berl) 116:56-64.

Shin RM, Tsvetkov E, Bolshakov VY (2006) Spatiotemporal asymmetry of associative synaptic plasticity in fear conditioning pathways. Neuron 52:883-896.

Shumyatsky GP, Tsvetkov E, Malleret G, Vronskaya S, Hatton M, Hampton L, Battey JF, Dulac C, Kandel ER, Bolshakov VY (2002) Identification of a signaling network in lateral nucleus of amygdala important for inhibiting memory specifically related to learned fear. Cell 111:905-918.

Sigurdsson T, Doyere V, Cain CK, Ledoux JE (2007) Long-term potentiation in the amygdala: a cellular mechanism of fear learning and memory. Neuropharmacology 52:215-227.

Silberman Y, Shi L, Brunso-Bechtold JK, Weiner JL (2008) Distinct mecha- nisms of ethanol potentiation of local and paracapsular GABAergic synapses in the rat basolateral amygdala. J Pharmacol Exp Ther 324:251-260.

Sosulina L, Schwesig G, Seifert G, Pape HC (2008) Neuropeptide Y activates a G-protein-coupled inwardly rectifying potassium current and dampens excitability in the lateral amygdala. Mol Cell Neurosci 39:491-498.

Steveson TC, Mains RE, Keutmann HT, Eipper BA (1997) Role of phosphorylation in internalization of peptidylglycine $\alpha$-amidating monooxygenase. FASEB J 11:A1061.

Stork O, Ji FY, Obata K (2002) Reduction of extracellular GABA in the mouse amygdala during and following confrontation with a conditioned fear stimulus. Neurosci Lett 327:138-142.

Szinyei C, Heinbockel T, Montagne J, Pape HC (2000) Putative cortical and thalamic inputs elicit convergent excitation in a population of GABAergic interneurons of the lateral amygdala. J Neurosci 20:8909-8915.

Taylor GA, Rodriguiz RM, Greene RI, Daniell X, Henry SC, Crooks KR Kotloski R, Tessarollo L, Phillips LE, Wetsel WC (2008) Behavioral characterization of P311 knockout mice. Genes Brain Behav 7:786-795.

Thompson BL, Rosen JB (2000) Effects of TRH on acoustic startle, conditioned fear and active avoidance in rats. Neuropeptides 34:38-44.

Tully K, Li Y, Tsvetkov E, Bolshakov VY (2007) Norepinephrine enables the induction of associative long-term potentiation at thalamo-amygdala synapses. Proc Natl Acad Sci U S A 104:14146-14150.

Weisskopf MG, Ledoux JE (1999) Distinct populations of NMDA receptors at subcortical and cortical inputs to principal cells of the lateral amygdala. J Neurophysiol 81:930-934.

Weisskopf MG, Bauer EP, Ledoux JE (1999) L-type voltage-gated calcium channels mediate NMDA-independent associative long-term potentiation at thalamic input synapses to the amygdala. J Neurosci 19: 10512-10519.

Yarbrough GG, Kamath J, Winokur A, Prange AJ Jr (2007) Thyrotropinreleasing hormone (TRH) in the neuroaxis: therapeutic effects reflect physiological functions and molecular actions. Med Hypotheses 69: 1249-1256.

Yun H-Y, Milgram SL, Keutmann HT, Eipper BA (1995) Phosphorylation of the cytosolic domain of peptidylglycine $\alpha$-amidating monooxygenase. J Biol Chem 270:30075-30083.

Zeng H, Schimpf BA, Rohde AD, Pavlova MN, Gragerov A, Bergmann JE (2007) Thyrotropin-releasing hormone receptor 1-deficient mice display increased depression and anxiety-like behavior. Mol Endocrinol 21:2795-2804.

Zhang W, Carreno FR, Cunningham JT, Mifflin SW (2009) Chronic sustained hypoxia enhances both evoked EPSCs and norepinephrine inhibition of glutamatergic afferent inputs in the nucleus of the solitary tract. J Neurosci 29:3093-3102.

Zhou WL, Yan P, Wuskell JP, Loew LM, Antic SD (2008) Dynamics of action potential backpropagation in basal dendrites of prefrontal cortical pyramidal neurons. Eur J Neurosci 27:923-936. 